\title{
Rule-of-Thumb Behaviour and Monetary Policy
}

\author{
Jeffery D. Amato \\ Bank for International Settlements \\ Thomas Laubach \\ Board of Governors of the Federal Reserve System*
}

First version: April 2000

Revised: December 2001

\begin{abstract}
We investigate the implications of rule-of-thumb behaviour on the part of consumers or price setters for optimal monetary policy and simple interest rate rules. The existence of such behaviour leads to endogenous persistence in output and inflation; changes the transmission of shocks to these variables; and alters the policymaker's welfare objective. Our main finding is that highly inertial policy is optimal regardless of what fraction of agents occasionally follow a rule of thumb. We also find that the interest rate rule that implements optimal policy in the purely optimising case, and a first-difference version of Taylor's (1993) rule, have desirable properties in all of the cases we consider. By contrast, the coefficients in other optimised simple rules tend to be extremely sensitive with respect to the fraction of rule-of-thumb behaviour and changes in other parameters of the model.
\end{abstract}

JEL classification: E31, E32, E52.

Keywords: Rule of thumb, optimal monetary policy, interest rate rules.

*Amato: 4002 Basel, Switzerland, jeffery.amato@bis.org; Laubach: Washington, D.C. 20551, tlaubach@frb.gov. We gratefully acknowledge many helpful discussions with Michael Woodford, as well as comments from Jordi Gali (editor), Marc Giannoni, Patrick Minford, Ulf Soderstrom, Kostas Tsatsaronis, two anonymous referees, and participants at the LACEA 2000 annual meetings in Rio de Janeiro, the Konstanz Seminar 2000 and the Swiss Workshop on Theoretical Economics. All remaining errors are ours. The views expressed herein are those of the authors and do not necessarily reflect those of the Bank for International Settlements, the Board of Governors of the Federal Reserve System, or the staff of either institution. 


\section{Introduction}

The characterisation of desirable monetary policy has been the subject of a large body of recent research. The question of what constitutes "optimal" monetary policy within structural models derived from optimising behaviour of households and firms has been a particularly lively area. A number of these studies are based on models in which the non-neutrality of monetary policy is derived from assuming frictions to price adjustment on the part of imperfectly competitive firms (e.g. Ireland 1997, Rotemberg and Woodford 1997, Clarida et al. 1999, Woodford 1999b). In these models, the price decisions of firms that are optimal given the assumed frictions to price adjustment ${ }^{1}$ lead to a relation linking current inflation to a measure of the current output gap, or current marginal cost, and expected future inflation, which Roberts (1995) has called the "new-Keynesian Phillips curve." This desription of the supply side of the economy is usually complemented on the demand side by a standard Euler equation characterising households' optimal consumption choice.

A notable feature of such models is the absence of lagged variables in the structural equations. The dynamics of output and inflation depend entirely on expectations of future values of these variables as well as future monetary policy actions. From an empirical perspective, this class of models has been criticised as being unable to replicate the high serial correlation found in both output and inflation data of many industrialised economies, unless one is willing to assume a substantial degree of serial correlation in the structural disturbances of the model (Fuhrer 1997a,b).

The failure of the consumption Euler equation to capture the dynamics of aggregate nondurable consumption, let alone those of aggregate output, has been debated for a long time (Mankiw et al. 1985, Deaton 1992, and many others). One proposed solution that maintains the assumption of optimal consumption choice is to allow for habit formation in preferences. Habit formation has been shown to improve the fit of small-scale business cycle models on U.S. time series, including aggregate consumption data (e.g. Fuhrer 2000), as well as being able to explain various anomalies in the finance literature (e.g. see chapter 8 in Campbell, Lo and MacKinlay 1997). However, while habit formation may be useful in explaining various aspects of aggregate data, direct evidence for habit formation based on data at the household level is hard to find (e.g. Dynan 2000).

More recently, attention has focused on the question whether the new-Keynesian Phillips curve

\footnotetext{
${ }^{1}$ The frictions to price adjustment referred to are alternatively Taylor's (1979) overlapping contracts, Rotemberg's (1982) convex costs of price adjustment, or Calvo's (1983) constant hazard model of readjustment of prices.
} 
is able to explain the high serial correlation in inflation in the United States (Fuhrer and Moore 1995a) as well as other industrialised countries (Coenen and Wieland 2000). Fuhrer and Moore argue that the price setting problem underlying the new-Keynesian Phillips curve is misspecified, and propose a contracting specification in which price setters are concerned about their relative real contract price. However, their specification seems at odds with optimising behaviour, since profit maximisation motivates only a concern for relative nominal contract prices or wages. On the other hand, Sbordone (2001) and Gali and Gertler (1999) provide evidence that the source of inflation inertia arises from the sluggish response of firms' real marginal cost to fluctuations in output.

An alternative approach to explaining the apparent dependence of current values of output and inflation on past as well as expected future conditions is to allow the choices of some agents to deviate from optimal behaviour due to, e.g., limits on their capacity to form fully rational expectations. Roberts (1997) considers deviations from rational expectations formation on the part of price setters. Similarly, Gali and Gertler (1999) derive a structural relationship explaining current inflation as depending on lagged inflation as well as current marginal cost and expected future inflation by assuming that a fraction of firms set prices by following a rule of thumb, while the remaining firms set prices in the optimal, forward-looking manner.

This article studies the implications for optimal monetary policy of rule-of-thumb behaviour. We believe there are compelling reasons for considering such behaviour, for example, the managerial costs involved in changing prices (Zbaracki et al. 2000). In fact, recently there has been general interest in the implications of optimisation costs for consumption choice (Gabaix and Laibson 2001) and price setting (Mankiw and Reis 2001). We take a slightly different approach than these authors by following Gali and Gertler. The rules of thumb that we consider specify that decisions by a fraction of the population ("rule-of-thumbers") today mimic yesterday's behaviour of all agents (i.e. including "optimising" agents). We assume that optimisation costs are independent random draws. ${ }^{2}$ Those whose cost exceeds a certain threshold use instead a rule of thumb. These rules are appealing for at least three reasons. First, they involve virtually no computational burden: all that is needed is for agents to observe last period's consumption or price setting decisions. Second, they involve passive learning of the behaviour of optimising agents. ${ }^{3}$ Third, all agents behave identically

\footnotetext{
${ }^{2}$ Dotsey et al. (1999) use a similar device in their model of state-dependent pricing.

${ }^{3}$ While we do not specify optimal learning rules, the complexity of such rules would impose a large computational burden upon agents, and would contradict the spirit of our approach.
} 
in the steady state. That is, there is convergence among individual choices once the effects of all shocks are eliminated from the economy.

One of the main purposes of this study is to provide a bridge between the studies assessing optimal monetary policy alluded to above - studies with purely forward-looking dynamics (i.e. with optimising agents) - and models with lagged dynamics imposed. One main advantage of our approach is that we can characterise precisely how lagged endogenous variables enter the model equations. Taking the standard dynamic new Keynesian model as our reference point, we introduce departures from optimising behaviour in exactly symmetrical fashion on both the supply and the spending side of the economy. Moreover, introducing lagged endogenous variables in a utility-based framework with a representative agent is compatible with the evaluation of the effects of monetary policy based on the maximisation of households' welfare.

As the incidence of rule-of-thumb behaviour increases, there are two changes in the model that have consequences for optimal policy. Of greatest importance, the transmission of shocks to the economy changes. Of less significance, the objective for monetary policy is also altered. The existence of rule-of-thumb price setting increases the degree of endogenous inflation persistence, and therefore makes shocks to inflation more long-lived, and inflation more variable. But rule-of-thumb behaviour also dampens the effects of shocks on inflation by reducing the sensitivity of inflation to the output gap. This latter effect dominates the increase in persistence, leading to a decline in the variability of inflation. In addition, we show that the presence of rule-of-thumb price setting implies that the monetary authority should seek to stabilise the first difference of inflation, as well as pursuing the standard goals of inflation and output gap stabilisation (see, e.g., Rotemberg and Woodford 1997). The adaptation of monetary policy to this change in objectives helps contribute further to the reduction in the variance of inflation in equilibrium. At the same time, the output gap becomes more volatile, because monetary policy is now less effective in influencing changes in current and expect future real interest rates due to greater persistence in expected inflation resulting from the rule of thumb. Overall, it turns out that there is very little change in the desired dynamic response of interest rates to shocks with respect to changes in the fraction of rule-of-thumb price setting behaviour.

Similarly, the presence of rule-of-thumb consumption behaviour increases the endogenous persistence in output (and the output gap); dampens the impact of shocks on output; and supplements the standard policy objective with a desire to smooth fluctuations in output growth. In addition, 
rule-of-thumb consumption affects the process governing the natural rate of interest, the summary statistic of the shocks to our model economy. ${ }^{4}$ The main effect of these changes is that the economy becomes easier to stabilise because the transmission of shocks to the output gap, and hence inflation, is reduced in magnitude. However, monetary policy now faces a trade-off between, on the one hand, inflation and output gap stabilisation, and on the other hand, output growth stabilisation. This implies that increasingly less importance is attached to stabilising inflation as the prevalence of rule-of-thumb consumption behaviour grows.

In addition to investigating the effects of rules of thumb on optimal monetary policy, we explore the properties of simple interest rate rules as a means for implementing policy. Our most striking result is that a highly inertial interest rate policy is desirable, as characterised by a feedback coefficient greater than one on the lagged interest rate term in simple interest rate rules. This finding is valid even when the vast majority of price or consumption choices are made using the rule of thumb, and is robust across a wide range of parameterisations. Our finding regarding the benefits of superinertial interest-rate setting affirms the conclusions of Rotemberg and Woodford (1999) and Woodford (1999b), who were the first to argue in favour of this type of policy within the context of a completely forward-looking model. It also stands in direct contrast to the suggestion (e.g. Taylor 1999a) that such an inertial interest rate policy ceases to be optimal, or even feasible, once backward-looking behaviour is incorporated into the structure of the model. ${ }^{5}$

Finally, our examination of various forms of rules suggests that the rule which implements the optimal plan in the situation when agents are always acting optimally continues to be nearly optimal under arbitrary degrees of rule-of-thumb behaviour. However, we show that the optimal coefficients in simpler versions of this rule change significantly in the presence of rules of thumb. Interestingly, a first-difference version of Taylor's (1993) original rule exhibits desirable welfare properties in all the cases we investigate.

The remainder of the article is structured as follows. The next section lays out our model,

\footnotetext{
${ }^{4}$ When investigating the robustness of our results from our baseline model, we also allow for inefficient supply shocks to buffet the economy.

${ }^{5}$ In our context, "backward-looking" behaviour refers to the use of rules of thumb. Taylor provides a comparative analysis of rules that feature desirable properties in at least one of the papers in the same volume. His study shows that Rotemberg and Woodford's (1999) superinertial rule leads to explosive solutions in models that do not explicitly contain expectational terms (e.g. Rudebusch and Svensson 1999) and sub-optimal performance in models that are not completely based on optimising behaviour (e.g. the models examined in Levin et al. 1999).
} 
including the introduction of rule-of-thumb consumers and price setters into an otherwise standard sticky-price optimising framework. It also gives the representation of households' welfare that monetary policy seeks to maximise. The section ends with a brief comparison of our approach to related literature. Section 3 describes our calibration of the model, and then analyzes the implications of rule-of-thumb behaviour for optimal monetary policy and interest rate rules. Section 4 examines the robustness of our results for policy. Section 5 offers conclusions. The derivation of several results is taken up in Appendix A; some calibration issues are discussed in Appendix B; and the conditions characterising optimal policy are given in Appendix C.

\section{A Structural Model with Rule-of-Thumb Behaviour}

To analyze the consequences for optimal monetary policy of rule-of-thumb behaviour by a fraction of agents, we use a small structural model derived from optimising behaviour of households and imperfectly competitive suppliers. Except for the presence of rule-of-thumb behaviour, our model is identical to that of Woodford (1999b). Specifically, we assume that the economy consists of a continuum of households, each of which is the monopolistic supplier of one differentiated product. Because households derive utility from consuming an aggregate of the differentiated products, suppliers face a downward-sloping demand schedule for their product. To keep the model as simple as possible, the economy is assumed closed, and there is no capital accumulation, so that goods market clearing requires that all output is being consumed each period.

In this section, we derive the implications of the presence of rule-of-thumb consumers for the relationship between expected future real interest rates and aggregate demand for output, and of rule-of-thumb price setting for the relationship between output and inflation. Next, we derive an approximation to the representative household's welfare in the presence of both rule-of-thumb consumers and rule-of-thumb price setters. Finally, we briefly compare our approach to some alternatives to introducing lagged dynamics into the structural equations.

\subsection{Rule-of-Thumb Consumers and Aggregate Demand}

There is a continuum of consumer-producers, each of them indexed by the product $i \in[0,1]$ of which it is the monopolistic producer. We depart from the standard infinite-horizon problem by assuming that at the beginning of each period, each household learns whether it is able to choose consumption 
optimally, or whether instead it chooses consumption based on a simple rule of thumb. Let $\psi$ denote the probability that a household is able to optimise, which is independent of the household's history. Thus, by the law of large numbers, in each period a fraction $\psi$ of households chooses consumption optimally. The remaining fraction $1-\psi$ chooses its consumption in period $t, C_{t}^{r}$, following the simple rule of thumb

$$
C_{t}^{r}=C_{t-1}
$$

where $C_{t}$ denotes aggregate per capita consumption in period $t$. Our modification to the standard consumer's problem is based on the premise that it is costly to reoptimise every period. Therefore agents might search for simple rules of thumb to use occasionally as an alternative to optimisation. The notion that optimisation costs lead agents to deviate from behaving optimally each period has been pursued in other recent work by Gabaix and Laibson (2001), to help explain the equity premium puzzle, and by Mankiw and Reis (2001), to help explain the persistence in inflation. ${ }^{6}$

Household $i$ 's objective is therefore to maximise

$$
E_{0} \sum_{t=0}^{\infty} \beta^{t}\left[\psi u\left(C_{t}^{i} ; \xi_{t}\right)+(1-\psi) u\left(C_{t}^{r} ; \xi_{t}\right)-v\left(y_{t}(i) ; \xi_{t}\right)\right]
$$

where $C_{t}^{i}$ is household $i$ 's consumption of the usual Dixit-Stiglitz aggregate when it is choosing consumption optimally. Each household considers itself too small to affect $C_{t}^{r}$, so that it maximises (2) over the sequence $\left\{C_{t}^{i}\right\}$, subject to its budget constraint and the constraint that its supply of its product equals demand,

$$
y_{t}(i)=\left(\frac{p_{t}(i)}{P_{t}}\right)^{-\theta} Y_{t}
$$

Here $p_{t}(i)$ denotes the price that household $i$ charges per unit of its product, $\theta$ denotes the elasticity of substitution between products in the index $C_{t}$, and $P_{t}$ and $Y_{t}$ denote the utility-based price index and the aggregate of individual households' output, respectively, corresponding to the aggregate $C_{t}$. The vector-valued random disturbance $\xi$ in (2) represents taste shifters affecting the utility of consumption, $u(\cdot ; \xi)$, and the disutility of supply, $v(\cdot ; \xi)$. The effects of $\xi$ on $u$ and $v$ are not required to be mutually orthogonal.

In formulating the household's budget constraint, we assume that financial markets are complete, and that households can insure themselves against all idiosyncratic risk, in particular the

\footnotetext{
${ }^{6}$ See section 2.4 for further discussion of Mankiw and Reis' approach.
} 
income risk arising from dispersion of prices across households, and the risk from choosing consumption optimally or according to the rule of thumb. Because households are identical ex ante, they are willing to enter such insurance contracts. One advantage of maintaining the set-up of a representative agent is that it keeps the analysis tractable, as otherwise the entire distribution of households' wealth would become a state variable. Under these assumptions, all households that have the opportunity to choose consumption optimally make the same choice, which we denote by $C_{t}^{o}$. Thus, per capita consumption in period $t$ is given by $C_{t} \equiv \psi C_{t}^{o}+(1-\psi) C_{t}^{r}$.

The rule (1) has the important feature that rule-of-thumb consumers learn from optimising households with one period delay. Hence, although consumption choice according to (1) is obviously not optimal, it embodies the three properties mentioned in the introduction; namely, agents are not required to compute anything; rule of thumbers learn from optimising households, because last period's decisions by the latter are part of $C_{t-1}$; and, differences between $C_{t}^{r}$ and $C_{t}^{o}$ will always remain bounded, and will be zero in the steady state.

Goods market clearing requires that $C_{t}=Y_{t} \forall t$. Hence (1) implies that $C_{t}^{r}=Y_{t-1}$, and therefore

$$
C_{t}^{o}=\psi^{-1}\left(Y_{t}-(1-\psi) Y_{t-1}\right)
$$

As shown in appendix A, taking a log-linear approximation of the first-order condition characterising the optimal choice of $C_{t}^{o}$ and substituting from (4) leads to an intertemporal IS equation of the form

$$
y_{t}-\tilde{g}_{t}=(1-\delta) y_{t-1}+E_{t}\left[\delta y_{t+1}-\tilde{g}_{t+1}\right]-\tilde{\sigma}^{-1}\left[r_{t}-E_{t} \pi_{t+1}\right]
$$

Here, $y_{t}$ denotes the percent deviation of aggregate output from its steady-state level, $\pi_{t}$ is the growth rate of the aggregate price index, i.e. $\pi_{t} \equiv \log \left(P_{t} / P_{t-1}\right)$, and $r_{t}$ is the nominal interest rate on a one-period riskless bond. ${ }^{7}$ The parameter $\psi$ enters (5) through $\delta \equiv \frac{1}{2-\psi}, \tilde{\sigma}^{-1} \equiv \frac{\psi}{2-\psi} \sigma^{-1}$, and $\tilde{g}_{t} \equiv \frac{\psi}{2-\psi} g_{t}$. The parameter $\sigma^{-1}$ measures the intertemporal elasticity of substitution in consumption. The term $g_{t}$ represents variation in spending that is not caused by changes in the real interest rate, such as disturbances to the marginal utility of consumption caused by fluctuations in $\xi_{t}$.

\footnotetext{
${ }^{7}$ More specifically, all log-linearizations are taken around a steady state with zero inflation. Hence, $\pi_{t}$ is by definition the percent deviation from its steady-state value, while $r_{t}$ denotes the percent deviation of the interest rate from its steady-state value associated with zero inflation.
} 
In the case where all households are able to choose consumption optimally, i.e. $\psi=1$, (5) reduces to the standard intertemporal IS equation

$$
y_{t}-g_{t}=E_{t}\left[y_{t+1}-g_{t+1}\right]-\sigma^{-1}\left[r_{t}-E_{t} \pi_{t+1}\right]
$$

that characterises the demand side in the models of Woodford (1996, 1999b), McCallum and Nelson (1999a), Clarida et al. (1999), and many other studies. The key difference between (5) and (6) is the effect of lagged on current output in the presence of rule-of-thumb consumers. Furthermore, smaller values of $\psi$ reduce the effects of both the expected real interest rate (through smaller values of $\tilde{\sigma}^{-1}$ ), and of the disturbance $g_{t}$, on current output.

A variable that plays an important role in the analysis below is the output gap, $x_{t} \equiv y_{t}-y_{t}^{n}$, where $y_{t}^{n}$ denotes the "natural rate of output", the level of output that would obtain if prices were completely flexible. The IS equation (5) can be expressed in terms of the output gap as

$$
x_{t}=(1-\delta) x_{t-1}+\delta E_{t} x_{t+1}-\tilde{\sigma}^{-1} E_{t}\left[r_{t}-\tilde{r}_{t}^{n}-\pi_{t+1}\right]
$$

where

$$
\tilde{r}_{t}^{n} \equiv \tilde{\sigma} E_{t}\left[\delta y_{t+1}^{n}+(1-\delta) y_{t-1}^{n}-y_{t}^{n}-\left(\tilde{g}_{t+1}-\tilde{g}_{t}\right)\right]
$$

is the "natural rate of interest", the real interest rate that would obtain if all prices were flexible, and that would correspond to the equilibrium nominal interest rate in the case of price stability. The natural rate of interest in the special case that $\psi=1$, which we denote by $r_{t}^{n}$, is defined by

$$
r_{t}^{n} \equiv \sigma E_{t}\left[y_{t+1}^{n}-y_{t}^{n}-\left(g_{t+1}-g_{t}\right)\right]
$$

\subsection{Rule-of-Thumb Price Setters and Aggregate Supply}

Real effects of monetary policy arise in this model from the assumption that within a given period not all suppliers are able to adjust their prices in response to fluctuations in demand. Specifically, we follow Calvo (1983) in assuming that each period a fraction $1-\alpha$ of suppliers is offered the opportunity to choose a new price, while the remaining suppliers have to maintain whichever price they charged before. Moreover, suppliers are drawn randomly and independent of their own history, in particular, independent of the time they were last offered the opportunity to adjust their price.

Our departure from the standard Calvo framework is exactly analogous to our departure from optimal consumption choice in the previous subsection. In addition to the costs of actually changing 
prices, such as menu costs or loss of goodwill, we assume that there are also costs involved with optimisation. At the beginning of each period, those agents who are offered the opportunity to reset their price learn whether they are choosing a new price by solving their optimisation problem, or by using the rule of thumb instead. Specifically, whenever a firm finds itself changing its price, with probability $\lambda$ it will reoptimise, and with probability $1-\lambda$ it will follow the rule of thumb. As with consumption choice, this interpretation of rule-of-thumb behaviour means we can still analyze price setting using a representative agent.

Those suppliers who do not set their prices in the optimal manner (described below), use the rule of thumb of Gali and Gertler (1999) by setting their price, which we denote by $p_{t}^{r}$, according to

$$
p_{t}^{r}=P_{t-1}^{*} \cdot \frac{P_{t-1}}{P_{t-2}}
$$

where $P_{t}^{*}$ is the aggregate of the prices newly chosen in period $t$ by both optimising and rule-ofthumb price setters. Like the rule (1), the rule (10) has the property that it relies on prices chosen by optimising price setters in the previous period. Using U.S. data, Gali and Gertler find support for hybrid price-setting rules of this type, in which a small but significant fraction of agents follow the rule of thumb given in (10). ${ }^{8}$

In deriving the optimal reset price, we assume that all consumers are able to choose consumption optimally, i.e. that $\psi=1$, so that the marginal utility of consumption is identical across consumerproducers. Since every supplier faces the same demand function (3), all optimising suppliers chosen in period $t$ to adjust their price will choose the same price, which we denote by $p_{t}^{o}$, and which maximises

$$
E_{t}\left\{\sum_{j=0}^{\infty}(\alpha \beta)^{j}\left[\frac{u_{c}\left(Y_{t+j} ; \xi_{t+j}\right)}{P_{t+j}}\left(\frac{p_{t}^{o}}{P_{t+j}}\right)^{-\theta} Y_{t+j} p_{t}^{o}-v\left(\left(\frac{p_{t}^{o}}{P_{t+j}}\right)^{-\theta} Y_{t+j} ; \xi_{t+j}\right)\right]\right\}
$$

The first term in brackets represents the household's utility from consumption in period $t+j$ if it chooses price $p_{t}^{o}$ in the current period. It is the product of its revenue in period $t+j$ conditional on its price being $p_{t}^{o}$, and the marginal utility of income in period $t+j, u_{c}\left(Y_{t+j} ; \xi_{t+j}\right) / P_{t+j}$. The second term represents the disutility incurred from supplying the amount of its product demanded in period $t+j$ if its price is still $p_{t}^{o}$. Since the price chosen in period $t$ will still be in effect in period $t+j$ with probability $\alpha^{j}$, the household discounts the stream of future utilities conditional on its

\footnotetext{
${ }^{8}$ Gali et al. (2001) provide similar evidence for the Euro area.
} 
choice of price today by the factor $\alpha \beta$.

The assumption that suppliers are offered the opportunity to reset their price independent of their history leads to a simple law of motion for the aggregate price index. Combining this law of motion with equations (11) and (10) then leads to a modified version of the new Keynesian Phillips curve (derived in appendix A)

$$
\pi_{t}=\tilde{\kappa} x_{t}+\gamma^{b} \pi_{t-1}+\gamma^{f} E_{t} \pi_{t+1}
$$

The coefficients $\tilde{\kappa}, \gamma^{b}$, and $\gamma^{f}$ are functions of the structural parameters $\beta, \sigma, \theta, \alpha, \lambda$, and the parameter $\omega$ measuring the elasticity of the disutility function $v$. Depending on the value of $\lambda$, the coefficients $\gamma^{b}$ and $\gamma^{f}$ sum to between $\beta$ (for $\lambda=1$ ) and 1 (for $\lambda=0$ ). With $\beta$ typically close to one, the values of $\gamma^{b}$ and $\gamma^{f}$ are readily interpretable as the relative weights on lagged and expected inflation. ${ }^{9}$ Despite our slightly different interpretation of rule-of-thumb behaviour, (12) is identical to the log-linear approximation derived by Gali and Gertler (1999). ${ }^{10}$

In the case that all price setters are optimising, i.e. $\lambda=1,(12)$ reduces to the "new-Keynesian Phillips curve"

$$
\pi_{t}=\kappa x_{t}+\beta E_{t} \pi_{t+1}
$$

where $\kappa \equiv \frac{(1-\alpha)(1-\alpha \beta)}{\alpha} \frac{\sigma+\omega}{1+\omega \theta}$, and the coefficients $\tilde{\kappa}$ and $\kappa$ are related by $\tilde{\kappa}=\frac{\lambda \alpha}{\alpha+(1-\lambda)(1-\alpha(1-\beta))} \kappa$. Comparing (12) and (13), the most important effect of allowing for rule-of-thumb behaviour is that current inflation is now in part determined by lagged inflation. For smaller values of $\lambda$, the importance of the lagged inflation term relative to expected inflation increases. Moreover, smaller values of $\lambda$ reduce the sensitivity of current inflation to fluctuations in the current output gap by reducing $\tilde{\kappa}$.

\footnotetext{
${ }^{9}$ Many authors have utilised a Phillips curve equation similar to (12), with the weights on expected and lagged inflation restricted to sum to one. A prominent example is the specification of Fuhrer and Moore (1995a), in which both coefficients are 1/2. For our choices of $\alpha$ and $\beta$ discussed in section 3.1, $\gamma^{b}$ and $\gamma^{f}$ are both equal to .499 when $\lambda=1-\alpha \beta=.3466$.

${ }^{10}$ Gali and Gertler assume that firms are divided into two groups, some that optimise every time they have the opportunity to change their price, and others who use the rule of thumb whenever they reset their price. By contrast, we assume that together with the signal to reset its price each firm receives a random signal to either optimise or follow the rule of thumb.
} 


\subsection{Welfare Implications of Rule-of-Thumb Behaviour}

One effect of allowing for rule-of-thumb behaviour is that lagged endogenous variables appear in equations (5) and (12). A second implication of allowing for rule-of-thumb behaviour, not previously noted in the literature, is that it affects the objective that monetary policy seeks to achieve. The early literature on desirable stabilisation policy, such as Taylor (1979), postulates that the objective for monetary policy should be to minimise some combination of the variances of inflation and either output or the output gap. Within the context of an optimisation-based model similar to the one above, but absent rule-of-thumb behaviour, Rotemberg and Woodford (1997) and Woodford (1999a) show that maximisation of the representative household's welfare indeed implies minimisation of the variances of inflation and the output gap, where the relative weights on inflation and output gap stabilisation are determined by the model's structural parameters.

To describe how rule-of-thumb behaviour affects the objective for monetary policy, suppose that monetary policy chooses at some point $t=0$ a plan that maximises the representative household's welfare, defined by

$$
E_{0}\left\{\sum_{t=0}^{\infty} \beta^{t}\left[\psi u\left(C_{t}^{o} ; \xi_{t}\right)+(1-\psi) u\left(C_{t}^{r} ; \xi_{t}\right)-\int_{0}^{1} v\left(y_{t}(i) ; \xi_{t}\right) d i\right]\right\}
$$

The integral over $v\left(y_{t}(i) ; \xi_{t}\right)$ is taken in order to abstract from the effects on an individual household's supply of the particular date at which it last had the opportunity to adjust its price. We evaluate alternative policies by taking the unconditional expectation of (14) with respect to the distribution of exogenous shocks, and under the assumption that all endogenous variables in the initial period are at their unconditional expectation of zero, to ensure that the desirability of the chosen plan does not depend upon initial conditions at time $0 .{ }^{11}$

In appendix A, we show that a second-order Taylor series expansion of (14) around the same steady state used to derive (5) and (12) can be expressed in the form of a loss function

$$
W=\sum_{t=0}^{\infty} \beta^{t} E_{0} L_{t}
$$

where the period-loss $L_{t}$ depends on the values of the parameters $\psi$ and $\lambda$. We first discuss the loss function in the case $\lambda=\psi=1$, and then consider the cases in which either $\psi$ or $\lambda$ are different

\footnotetext{
${ }^{11}$ This allows us to view our time-invariant rules as approximations to an optimal plan that does not exploit initial conditions. See Woodford (1999a) for further discussion of this point.
} 
from $1 .^{12}$

In the special case without rule-of-thumb behaviour, i.e. $\lambda=\psi=1$, the period-loss function $L_{t}$ is given by

$$
L_{t} \equiv \pi_{t}^{2}+\lambda_{x} x_{t}^{2}
$$

where $\lambda_{x} \equiv \kappa / \theta$. Consequently, after taking the unconditional expectation of (15) to abstract from initial conditions (as discussed above), the loss function becomes

$$
E(W)=V\left[\pi_{t}\right]+\lambda_{x} V\left[x_{t}\right]
$$

where the measure of variability for any variable $z$ that is used here is defined by

$$
V[z] \equiv E\left[(1-\beta) \sum_{t=0}^{\infty} \beta^{t} E_{0} z_{t}^{2}\right]
$$

Except for discounting, this measure corresponds to the unconditional variance of $z_{t}$. The objective (16) is analyzed, e.g., by Clarida et al. (1999).

The model presented above has the property that fluctuations in the output gap are the only source of inflation variability, as can be seen from (12). It is therefore possible to completely stabilise both inflation and the output gap in response to fluctuations in $r_{t}^{n}$, and hence no tradeoff exists between the goals of output gap stabilisation and inflation stabilisation. A number of reasons, however, have been advanced why interest rate variability, in addition to inflation and output gap variability, should be undesirable. These include the optimal choice of nominal money balances and aspects of financial stability. In addition, within the confines of our stylised model, Rotemberg and Woodford (1997) emphasise that for a sufficiently variable process $\left\{r_{t}^{n}\right\}$, complete stabilisation of the output gap requires interest rate variability sufficiently high such that a positive steady-state rate of inflation is necessary to avoid the zero lower bound on nominal interest rates, and that such steady-state inflation is welfare reducing due to its effects on relative price dispersion. ${ }^{13,} 14$

\footnotetext{
${ }^{12}$ For clarity of exposition, we do not consider the situation in which both $\psi$ and $\lambda$ are different from 1 , but the extension of the current analysis to this case is straightforward.

${ }^{13}$ The second-order approximation of welfare given by (16) assumes that both $\pi_{t}$ and $x_{t}$ have steady-state values of 0 . To account for the possibility that steady-state inflation $\bar{\pi}$ will be non-zero under the optimal policy requires (16) to be augmented by the term $\bar{\pi}^{2}$. In addition, the proper loss function contains a similar term related to the steady-state level of the output gap $\bar{x}$ equal to $\lambda_{x} \bar{x}^{2}$. Absent rule-of-thumb price setters, (13) implies that $\bar{x}=\frac{1-\beta}{\kappa} \bar{\pi}$. With rule-of-thumb price setters, $\bar{x}$ is obtained from (12). Thus, in the light of the zero lower bound, a trade-off arises between stabilising inflation and achieving a low average level of inflation.

${ }^{14}$ Independently, there are other reasons to expect that steady-state inflation is welfare reducing, which we have
} 
Whatever the reason why interest rate variability is undesirable, it may generate a tradeoff between stabilising inflation and the output gap on one hand, and interest rates on the other. We evaluate alternative policies based on a modification of (16) given by

$$
\hat{W}=V\left[\pi_{t}\right]+\lambda_{x} V\left[x_{t}\right]+\lambda_{r} V\left[r_{t}\right]
$$

The choice of the weight $\lambda_{r}$ will be discussed in the following section.

In the presence of rule-of-thumb price setters (but absent rule-of-thumb consumers), the periodloss function becomes

$$
L_{t}^{p} \equiv \pi_{t}^{2}+\lambda_{x} x_{t}^{2}+\lambda_{\Delta \pi}\left(\pi_{t}-\pi_{t-1}\right)^{2}
$$

while the criterion for evaluating alternative policies is given by

$$
\hat{W}^{p}=V\left[\pi_{t}\right]+\lambda_{x} V\left[x_{t}\right]+\lambda_{\Delta \pi} V\left[\pi_{t}-\pi_{t-1}\right]+\lambda_{r} V\left[r_{t}\right]
$$

where $\lambda_{\Delta \pi} \equiv \frac{1-\lambda}{\alpha \lambda}$. The fact that now a fraction $1-\lambda$ of price setters is learning about the optimal price by observing the average of prices set in the previous period creates a rationale for reducing variability in the change of inflation. The only effect of this additional term is to increase the weight on inflation stabilisation relative to output gap stabilisation, since any reduction in inflation variability reduces the variability of the change in inflation as well. ${ }^{15}$ The additional term in the loss function in particular does not generate any new tradeoffs between stabilisation of the various variables, since price stability still achieves the minimum of all three terms entering (18). Hence, even in the presence of rule-of-thumb price setters, the only potential tradeoff is due to the penalty on interest rate variability.

In the presence of rule-of-thumb consumers (but absent rule-of-thumb price setters), the periodloss function becomes

$$
L_{t}^{c} \equiv \pi_{t}^{2}+\lambda_{x} x_{t}^{2}+\lambda_{\Delta y}\left(y_{t}-y_{t-1}\right)^{2}
$$

while the objective that monetary policy seeks to minimise is given by

$$
\hat{W}^{c}=V\left[\pi_{t}\right]+\lambda_{x} V\left[x_{t}\right]+\lambda_{\Delta y} V\left[y_{t}-y_{t-1}\right]+\lambda_{r} V\left[r_{t}\right]
$$

not explored in the present paper. These include distortions emanating from the interaction of inflation with the tax code and long-range planning uncertainties.

${ }^{15}$ To see this, note that

$$
V\left[\pi_{t}\right]+\frac{1-\lambda}{\alpha \lambda} V\left[\pi_{t}-\pi_{t-1}\right]=\left(1+\frac{2(1-\lambda)\left(1-\rho_{\pi}\right)}{\alpha \lambda}\right) V\left[\pi_{t}\right]
$$

where $\frac{1-\lambda}{\alpha \lambda} \geq 0$ and $\rho_{\pi}$ is the first-order autocorrelation of inflation in equilibrium. Since $\left|\rho_{\pi}\right|<1,1+\frac{2(1-\lambda)\left(1-\rho_{\pi}\right)}{\alpha \lambda} \geq 1$. 
where $\lambda_{\Delta y} \equiv \frac{\sigma}{\sigma+\omega} \frac{1-\psi}{\psi} \lambda_{x}$. When a fraction $1-\psi$ of households is choosing consumption following the rule of thumb (1), fluctuations in output (not only in the output gap) create welfare losses, because changes in output cause larger departures of rule-of-thumb from optimal consumption. In contrast to the case of rule-of-thumb price setting, the presence of rule-of-thumb consumers does give rise to an additional tension among the various stabilisation goals in (20). In particular, even without the penalty on interest rate variability, the output variability that is necessary to keep output at its natural rate implies welfare losses according to the criterion (21).

\subsection{Alternative Approaches to Introducing Lagged Dynamics}

The criticism, from an empirical perspective, of the standard dynamic new Keynesian model with purely forward-looking structural equations, as represented by our equations (6) and (13), has spurred the search for explanations of the presence of lagged dynamics in the structural equations. Our rule-of-thumb specifications are one tractable way of achieving this. The purpose here is to briefly compare our specifications to two leading alternatives, namely habit formation in consumption, and a form of price indexation recently advanced by Christiano et al. (2001). This comparison should clarify that our specification is a reasonably general one, and can be given different interpretations.

Habit formation has recently been explored by McCallum and Nelson (1999b), Fuhrer (2000), and Amato and Laubach (2001a) in models for the analysis of monetary policy. A particularly simple way of introducing habit formation is to assume that the habit is exogenous (i.e. optimising consumers do not consider their current consumption to affect their future habit stock) and that labour supply is perfectly elastic, so that the habit affects only the spending side of the economy (as in McCallum and Nelson). Suppose that household $i$ maximises

$$
E_{0} \sum_{t=0}^{\infty} \beta^{t}\left[(1-\sigma)^{-1}\left(C_{t}^{i}\right)^{1-\sigma} C_{t-1}^{-h(1-\sigma)}\right]
$$

where the household's habit stock is given by lagged aggregate consumption $C_{t-1}$ to the power $h \in[0,1]$. For $h=0$, this is the standard time-separable utility specification. Log-linearising the Euler condition, one obtains the relation

$$
y_{t}=(1-\hat{\delta}) y_{t-1}+\hat{\delta} E_{t} y_{t+1}-\hat{\sigma}^{-1}\left[r_{t}-E_{t} \pi_{t+1}\right]
$$

which has the same form as (5) except that we omitted here the exogenous shocks $g_{t}$ (they can 
be introduced symmetrically). The coefficient $\hat{\delta}$ is given by $\sigma / \hat{\sigma}$, and $\hat{\sigma} \equiv \sigma+h(\sigma-1) .{ }^{16}$ The responsiveness of $\hat{\delta}$ and $\hat{\sigma}^{-1}$ to changes in $h$ depends on the size of $\sigma$. For values of $\sigma$ less than 6 we find that $\hat{\delta}$ and $\hat{\sigma}^{-1}$ respond less to changes in $h$ than $\delta$ and $\tilde{\sigma}^{-1}$ respond to changes in $\psi{ }^{17}$ Furthermore, as shown in Amato and Laubach (2001a), the approximation of the representative household's welfare takes a similar form as (21), although the weights are different.

An alternative to our rule-of-thumb price setting specification has been proposed by Christiano et al. (2001). They depart from the standard Calvo specification by assuming that each period a fraction $1-\alpha$ of producers can choose their price optimally, whereas the remaining producers update their individual prices using the previous period's aggregate inflation rate. This leads to an equation like (12), with the coefficients $\gamma^{b}$ and $\gamma^{f}$ given by $\frac{1}{1+\beta}$ and $\frac{\beta}{1+\beta}$ respectively. The coefficients sum to 1 , and for choices of $\beta$ close to 1 , both coefficients are close to $1 / 2$. To make their framework more comparable to ours, a straightforward generalisation is to assume that a fraction $\lambda$ of producers who do not reoptimise index their current price to the previous inflation rate, whereas the remaining firms keep their individual prices constant. In this case, by letting $\lambda$ decline from 1 to .1 , the coefficients $\left(\gamma^{b}, \gamma^{f}\right)$ change from $(0, \beta)$ to $(.48, .52)$ for $\beta=.99$. By comparison, for $\alpha=.66$ and $\beta=.99$, the coefficients $\left(\gamma^{b}, \gamma^{f}\right)$ in (12) correspondingly change from $(0, \beta)$ to $(.58, .42)$. Importantly, in Christiano et al.'s limiting case of $\lambda=0$, the traditional view of sticky prices as being caused (at least in part) by costs to price adjustment no longer applies, as all producers change their price every period whenever last period's inflation rate is different from zero. This is in stark contrast to evidence on price setting at the firm level discussed by, for example, Taylor (1999c). ${ }^{18}$ Finally, in the context of these alternative versions of price setting behaviour, one can once again derive an approximation to the representative household's welfare analogous to (19), with the same variables entering the loss function, although with weights different from ours.

\footnotetext{
${ }^{16}$ One important aspect to note is that this specification of habit formation requires $\sigma>1$ as only then a higher habit stock reduces the marginal utility of consumption.

${ }^{17}$ For example, when $\sigma=5$, the coefficient $\hat{\delta}$ decreases from 1 to .58 as $h$ increases from 0 to .9, whereas $\delta$ in (5), which is independent of $\sigma$, falls from 1 to .53 as $\psi$ declines from 1 to .1 (the equivalent change to that in $h$ ).

${ }^{18}$ Mankiw and Reis (2001) offer a model of imperfect price adjustment in which each firm is able to change its price every period, but the information set on which a firm bases its new price is updated randomly as in the Calvo framework. The infrequent updating of information sets has the implication that past endogenous variables, particularly past inflation, in part determines current prices. However, by allowing a firm to change its price every period, this specification is also inconsistent with the evidence in Taylor (1999c).
} 
Thus, while our preferred interpretation of the model given by (5) and (12) is the usage of rules of thumb such as (1) and (10), the discussion above shows that remarkably similar equations obtain under alternative assumptions. In this regard, our analysis of monetary policy becomes more widely applicable.

\section{Implications for Monetary Policy}

This section characterises how desirable monetary policy is affected as the fraction of agents using a rule of thumb varies. Throughout we assume that policymakers are able to act under commitment. We do not claim that the behaviour of policymakers is always best described by commitment, but neither do we believe, as has been argued, that monetary policy in the real world is clearly characterised by discretion. Our preference for commitment is based on our focus on analyzing feedback rules for the interest rate, which we interpret as a commitment device. Moreover, since it is well-known that there are substantial welfare gains to be reaped from commitment, we believe that the study of optimal policy is most persuasive if it is assumed that policymakers are capable of commitment.

We conduct the analysis separately under the two types of rule-of-thumb behaviour to clarify the implications of each for monetary policy. In each case, we first derive the optimal plan, that is the joint evolution of the endogenous variables that maximises the representative household's welfare (14). We then turn to the evaluation of simple interest rate rules, using the optimal plan as the benchmark. We are interested in examining a number of simple interest rules for two reasons. First, as we discuss below, the interest rate rules that would implement the optimal plan become quite complex in the presence of rule-of-thumb behaviour, involving many arguments, and the optimal weights of these arguments are functions of the fraction of rule-of-thumbers. Considering that it may be difficult to determine what fraction of agents uses rules of thumb, it would be desirable to find interest rate rules that are robust with respect to the fraction of rule-of-thumbers. Second, the calculation of optimal simple rules allows us to make direct comparisons to similar rules recommended by other authors (e.g. the various contributors to Taylor (1999b)). Specifically, one of the main purposes of this paper is to address whether super-inertial policy remains optimal in the presence of rule-of-thumb behaviour. In the context of simple rules this type of policy is interpreted as a coefficient greater than one on the lagged interest rate. The calculation of the 
optimal response to the lagged instrument is necessary because a measure of interest rate inertia from an unconditional autocorrelation function is misleading for this purpose. Such a measure captures persistence in interest rates due to persistence in other variables that enter the policy rule, as well as from responses to lagged interest rates. ${ }^{19}$

\subsection{Calibration}

Before proceeding to analyze the properties of optimal simple interest rate rules, we briefly discuss how we calibrate the model. The two equations (7) and (12) contain seven structural parameters $(\alpha, \beta, \sigma, \omega, \theta, \lambda$ and $\psi)$, for which values must be specified. Furthermore, the welfare objectives (17) and (21) depend upon the weight $\lambda_{r}$ on interest rate variability. When we examine the implications of introducing rule-of-thumb price setters (subsection 3.2), we fix $\psi$ at 1 and report results for $\lambda=1, .6, .2$; in subsection 3.3 , we instead focus on rule-of-thumb consumers by fixing $\lambda$ at 1 and reporting results for $\psi=1, .6, .2$. The remaining six parameters are chosen to equal those used by Woodford (1999b), which he obtained based on the estimation results of Rotemberg and Woodford (1997). These values are given in Table $1 .{ }^{20}$ Compared to other studies, the values of $\sigma$ and $\omega$ imply high elasticities of intertemporal substitution and labour supply, respectively. In section 4, we will assess the robustness of our results with respect to alternative values for these two parameters. The weight $\lambda_{r}$ reflects the concern for interest rate variability in Rotemberg and Woodford's model, which is due to the zero lower bound on nominal interest rates. For this parameter too we will later consider an alternative value.

The parameterisation and calibration of the shock process $r_{t}^{n}$ assumes that it is an $\operatorname{AR}(1)$ process. Its standard deviation is again equal to Woodford's value. In our baseline calibration we assume that $r_{t}^{n}$ is serially uncorrelated, which facilitates the interpretation of the impulse responses presented below, because in this case the only source of persistence is the model's endogenous dynamics. Later we will allow the serial correlation $\rho_{r}$ to be positive. The implied calibrations of the processes $g_{t}$ and $y_{t}^{n}$ are described in Appendix B.

We have three main reasons for calibrating the model in this way. First, Rotemberg and Woodford estimate a version of a fully specified general equilibrium model which comes closest to

\footnotetext{
${ }^{19}$ Persistence in these other variables, e.g. inflation, may arise due to endogenous persistence in the other structural relations of the model or from exogenous shocks.

${ }^{20}$ The parameters were chosen so that one period equals a quarter.
} 
matching our model equations and in which all of our structural parameters (except $\lambda$ and $\psi$ ) are present. ${ }^{21}$ Gali and Gertler (1999) estimate an equation for inflation in their model of rule-of-thumb price setters, thus providing estimates of the parameters $\alpha, \beta$ and $\lambda$. Our choice of $\alpha=0.66$ is slightly lower than their estimates, which are in the interval from 0.8 to 0.87 , although our value is well within the range of existing survey evidence (e.g. Blinder, 1994). Their estimates of $\lambda(0.48$ to 0.92 ) show that a wide range of values for this parameter are consistent with their data, but it is also clear that focusing on the range $\lambda>0.5$ is most realistic from an empirical perspective. ${ }^{22}$ Second, Rotemberg and Woodford's sequential estimation approach suggests that the values of the structural parameters they obtained remain empirically valid even if the processes for the exogenous shocks are misspecified. Third, one of our primary motivations is to assess whether Woodford's (1999b) finding about the desirability of inertial policy remains valid in the presence of backwardlooking behaviour, so using the same values for common parameters affords a direct comparison to his results.

\subsection{Results with Rule-of-Thumb Price Setters}

In this subsection, we consider the case of rule-of-thumb price setters, when the model's structural equations are given by (6) and (12). We begin by computing the optimal plan, i.e. the sequences $\left\{\pi_{t}, x_{t}, r_{t}\right\}_{t \geq 0}$ that maximise the welfare objective (19). The first-order conditions characterising the optimal plan are derived in appendix C. In Table 2 we report the variances of the variables entering the objective (19), and the value of the objective itself, for three different values of $\lambda$, the fraction of price setters who reset their price optimally. The first row under each value of $\lambda$ reports the statistics for the optimal plan.

As the results show, the weight on interest rate variability in the objective $\hat{W}^{p}$ introduces a nontrivial tradeoff among the variances of the endogenous variables, so that neither of the three variables is perfectly stabilised. In this model, even with rule of thumb price setters, the only trade-off present is between inflation and output gap variability on the one hand, and interest rate

\footnotetext{
${ }^{21}$ Unlike in the present case, Rotemberg and Woodford's model involves decision lags in consumption planning and time delays for a fraction of price setters in establishing newly chosen prices. However, by taking two-period expectations of their structural equations, one obtains (6) and (13).

${ }^{22}$ One reason for not using Gali and Gertler's results is that they estimate only a single equation model, and thus they do not provide the full set of parameters needed. An additional reason is that they estimate their model using data on real unit labour costs instead of the output gap, $x_{t}$.
} 
variability on the other. Moreover, as shown in section 2.3, the implicit overall weight on $V[\pi]$ increases as $\lambda$ becomes smaller. ${ }^{23}$ Therefore, for $\lambda<1$, the trade-off in the model favours relatively less inflation variability. However, the result that the two variances involving inflation decrease as $\lambda$ decreases, whereas the variances of the output gap and the interest rate increase, is only in part due to this changing tradeoff.

Changes in $\lambda$ have several implications besides changing the relative weights in the objective (19). Inspection of (12) reveals that there are two effects on the AS equation from varying $\lambda$. On the one hand, the degree of endogenous inflation persistence increases as $\lambda$ decreases, which, ceteris paribus, would imply higher inflation variability. On the other hand, the coefficient $\tilde{\kappa}$ declines with $\lambda$, implying that fluctuations in the output gap (due to discrepancies between the natural rate and the real rate of interest) have a weaker impact on inflation. As shown in Table 2, the latter effect dominates, as inflation variability decreases with $\lambda$ despite the slight increase in $V[x]$.

The slight increase in output gap and interest rate variability for lower values of $\lambda$ owes to the weaker response of expected inflation to anticipated monetary policy. This can be seen from Figure 1, which shows the impulse responses to a one standard deviation increase in the natural rate of interest. As shown in the bottom two panels, for any value of $\lambda$ the optimal responses of the nominal interest rate and the output gap are very persistent, exploiting expectations for stabilisation purposes as described by Woodford (1999b) by inducing a long-lived sequence of expected negative output gaps. This mechanism is remarkably invariant to changes in $\lambda$. However, the response of inflation to these sequences of expected output gaps is considerably more muted as $\lambda$ becomes small, because fewer price setters take these expected future output gaps into account when resetting their prices. The strong response of inflation in the period following the natural rate shock when $\lambda=1$ implies that, when the shock occurs, the increase in the nominal interest rate leads to a larger increase in the expected real interest rate which mitigates the effect of the shock on the output gap and hence inflation itself. As $\lambda$ becomes smaller, the same nominal rate increase is associated with a relatively smaller increase in the real interest rate. Thus the slight

\footnotetext{
${ }^{23}$ The standard variability frontiers presented in the literature are computed by changing the relative weights in the objective on the terms involved in the tradeoff. For an example of this type of frontier in the purely forward-looking version of our model, see Figure 6.1 in Woodford (1999a). But $\lambda$ is a structural parameter of the model here, so in addition to changing the relative weights in $\hat{W}^{p}$, the model equations are affected. Thus, changing $\lambda$ does not map out variability frontiers of the usual kind.
} 
increase in $V[r]$ shown in Table 2, also visible in the bottom panel of Figure 1, is not large enough to prevent $V[x]$ from rising.

To express the optimal plan in an operational form, we can solve the first-order conditions for the implied interest rate rule that implements the optimal plan. For the standard $(\lambda=1)$ case, Giannoni (2000) shows that the optimal rule is of the form

$$
r_{t}=a \pi_{t}+b\left(x_{t}-x_{t-1}\right)+c_{1} r_{t-1}+c_{2} r_{t-2}
$$

where the coefficients $a, b, c_{1}$, and $c_{2}$ are functions of the structural parameters. As usual in linearquadratic optimal control problems, the optimal rule is certainty-equivalent, i.e. the coefficients do not depend on the stochastic properties of $r^{n}$. However, as shown in appendix C, when $\lambda<1$ the "rule" implied by the optimal plan becomes considerably more complicated, involving not only expectations of inflation and the output gap, but also of the interest rate itself as arguments.

This motivates our analysis of a number of simple feedback rules for the interest rate. Besides examining how well the rule (24) does when $\lambda<1$, we also examine several versions of the rule

$$
r_{t}=a \pi_{t}+b x_{t}+c r_{t-1}
$$

with restrictions imposed on some or all of the three coefficients. ${ }^{24}$ Finally, in view of recent arguments in favour of interest rate rules with feedback from the price level instead of from inflation (e.g. Giannoni (2000) and Vestin (2000)) we also consider the rule

$$
r_{t}=a p_{t}+b x_{t}
$$

In this rule we omit feedback from the lagged interest rate because feedback from the price level has been advocated as an alternative mechanism for achieving the degree of history dependence characteristic of optimal monetary policy under commitment. For each rule we compute the coefficients (insofar as their values are not imposed) by minimising $\hat{W}^{p}$, and compare the resulting welfare level to that under the optimal plan. In the column labeled " $b$ " in Table 2 we report the coefficient on $\Delta x_{t}$ for rule (24), and the coefficient on $x_{t}$ for all other rules. In the column labeled " $c$ " we report the sum of the coefficients $c_{1}$ and $c_{2}$ for rule (24), and the coefficient on $r_{t-1}$ for all other rules.

\footnotetext{
${ }^{24}$ Because $V[\Delta \pi]$ enters the welfare objective when $\lambda<1$, we also considered rules with feedback from $\Delta \pi_{t}$ (and similarly with feedback from $\Delta y_{t}$ for rule-of-thumb consumers). As feedback from these variables turned out to be quantitatively unimportant, we omit the results.
} 
For each value of $\lambda$, the first rule we report is (24). For $\lambda=1$, this rule, of course, reproduces the optimal plan. The optimality of superinertia is shown by the sum of coefficients on the two lags of the interest rate being greater than 1. A rule of this form continues to approximate the optimal plan very closely even when $\lambda$ is as low as 0.2 (in which case, as discussed before, the rule implementing the optimal plan is considerably more complex). ${ }^{25}$ Moreover, the optimal parameters of this rule change only moderately. The key result is that superinertial behaviour of the interest rate remains optimal as $\lambda$ becomes small.

To assess the importance of superinertial behaviour for welfare we next compare four rules of the form (25) with $b=0$ imposed. ${ }^{26}$ We first compute the optimal coefficients $a$ and $c$ on $\pi_{t}$ and $r_{t-1}$, and then compare this rule to rules in which the coefficient $c$ is fixed at $1, .5$, and .2 respectively, and $a$ is chosen optimally. Several results emerge. First, the rule in which both $a$ and $c$ are chosen freely comes very close to replicating the optimal plan when $\lambda=1,{ }^{27}$ and involves only modest welfare losses compared to the optimal plan as $\lambda$ becomes smaller. Second, restricting $c$ to values less than or equal to 1 leads to some additional losses when $\lambda=1$, but these losses diminish as $\lambda$ gets smaller. For $\lambda=.2$, in fact, we find that the optimal value of $c$ is .65, i.e. for a rule of this form a response greater than one to the lagged interest rate is no longer optimal. Finally, an unappealing feature of a rule of this kind is the extreme sensitivity of the optimal coefficients with respect to $\lambda$. If, as is likely, the prevalence of rule-of-thumb behaviour is difficult to quantify, it would be important to find a rule that produces desirable results over a broad range of values for $\lambda$. We return to this issue momentarily.

The next three rules are again of the form (25), but now allowing for feedback from $x_{t}$. The first two of these impose $c=0$. By excluding feedback from the lagged interest rate, we can assess the importance of history dependence in monetary policy emphasised by Woodford (1999b).

\footnotetext{
${ }^{25}$ In a model closely related to ours, Giannoni and Woodford (2001) solve for the rule implementing the optimal plan in the presence of lagged inflation dynamics by substituting for the expected interest rate in terms of infinite lead polynomials of inflation and the output gap. They show that the coefficients on the two lags of the interest rate in this rule are nearly invariant to changes in the importance of the lagged inflation dynamics, whereas the coefficients on the expected inflation and output gap terms die out very rapidly regardless of the importance of lagged inflation.

${ }^{26}$ We do not report results when all three coefficients in (25) are chosen optimally because $a$ and $b$ are not welldetermined in this case.

${ }^{27}$ Woodford (1999b) reports the same finding. We will return to his results in the next section, when considering the case $\rho_{r}=.35$.
} 
The first rule allows for optimal choice of both $a$ and $b$, whereas the second rule fixes $a$ and $b$ at the values recommended in Taylor (1993). The third rule reintroduces history dependence by expressing the Taylor rule in terms of the first difference of the interest rate (hence labeled "Taylor FD" in the tables). History dependence is of first-order importance when $\lambda=1$, as seen by the poor performance of both rules with $c=0$, but becomes less important as the fraction of rule-of-thumb behaviour increases. For $\lambda=.2$, for example, the "a,b" rule performs about as well as any of the "a,c" rules analyzed before. More attractive is the "Taylor FD" rule, which combines the advantages of history dependence when $\lambda$ is reasonably large with robustness in terms of performance across different values of $\lambda$. Apparently, difference rules with $c=1$, as in the work of Fuhrer and Moore (1995b) and others, entail little welfare loss if enough price setters are using the rule of thumb. ${ }^{28}$ We thus find the Taylor FD rule to be an attractive alternative to rules of the form (24).

Finally, the price level rule (26) produces results most similar to the rule "a,c=1". Thus, while it does not reap the full advantages of history dependence when $\lambda=1$, it performs slightly better than any of the "a,c" rules when $\lambda=.2$. However, it shares with the "a,c" rules the drawback of extreme sensitivity of the coefficients with respect to changes in $\lambda$.

\subsection{Results with Rule-of-Thumb Consumers}

We next deal with the case when all price setters are optimising, but some fraction of consumers use a rule of thumb each period, i.e. the model equations are (7) and (13), and the welfare objective is (21). We undertake the analysis in the same way as in the previous subsection.

The first row under each value of $\psi$ in Table 3 reports again the optimal plan. ${ }^{29}$ For a fixed value of $\psi$, there is a tradeoff in this model between $V[\pi]$ and $V[\Delta y]$, in addition to the tradeoff created by the objective of interest rate stabilisation described above. As $\psi$ declines, the weight on $V[\Delta y]$ increases, so one might expect to see $V[\pi]$ and $V[r]$ increasing as $\psi$ declines, and the opposite for $V[\Delta y]$. However, changes in $\psi$ also affect elements of the model, as can be seen clearly from equation (7). On the one hand, smaller values of $\psi$ increase the degree of endogenous persistence in the output gap - as captured by $\delta$ converging to 0.5 from above as $\psi$ goes to 0 - thereby

\footnotetext{
${ }^{28}$ Amato and Laubach (2001b) make a similar point in the context of a purely forward-looking model with sticky prices and wages.

${ }^{29}$ The results for $\psi=1$ reported in Table 3 are identical to those for $\lambda=1$ reported in Table 2 , except that we report in Table 3 the value of $V[\Delta y]$ instead of $V[\Delta \pi]$.
} 
engendering greater variability in $x_{t}$. This mechanism is the same as the one described in the previous subsection for inflation.

On the other hand, smaller values of $\psi$ dampen the impact of gaps between the real and natural interest rates on $x_{t}$, reducing its variance. The dashed-dotted line in Figure 2 shows that, as $\psi$ declines, $\tilde{\sigma}$ increases, reducing the elasticity of output with respect to the expected real interest rate. At the same time, this change in elasticity requires that the variance of $\tilde{r}_{t}^{n}$ be increased to ensure that aggregate demand would equal the natural rate of output in a flexible price equilibrium. However, there is a second effect on $\tilde{r}_{t}^{n}$, which acts to reduce its variance. As equation (8) shows, the transmission of the shocks $y_{t}^{n}$ and $g_{t}$ to $\tilde{r}_{t}^{n}$ is dampened as $\psi$ declines. The quantitative effect of this dampening can be seen from the dashed line in Figure 2, which shows $s d\left(\tilde{r}_{t}^{n}\right) / \tilde{\sigma}$ as a function of $\psi \cdot{ }^{30}$ As the solid line shows, $s d\left(\tilde{r}_{t}^{n}\right)$ increases as $\psi$ declines, but, overall, changes in $\tilde{\sigma}$ and $s d\left(\tilde{r}_{t}^{n}\right)$ induce smaller fluctuations in $x_{t}$. As in the case with rule-of-thumb price setters, the increasingly weaker transmission of shocks as $\psi$ declines dominates the effect of stronger endogenous output (gap) persistence. This is shown by the dramatic decline in output gap variability reported in Table 3 despite a roughly proportional decline in interest rate variability.

The changes in the transmission of shocks to the economy as $\psi$ changes are illustrated in Figure 3. The figure presents the responses to a perturbation to the marginal utility of consumption of size one percent of steady-state output. ${ }^{31}$ For $\psi=1$ this shock acts much like the one to $r_{t}^{n}$ that we considered in the previous subsection, and the responses are qualitatively similar, although quantitatively different. This shock, working through $g_{t}$, affects both actual output (by an amount $\frac{\psi}{2-\psi}$ times $g_{t}$ ) and the natural rate of output (by an amount $\frac{\sigma}{\sigma+\omega}$ times $g_{t}$ ). The factor $\frac{\sigma}{\sigma+\omega}$ is about $1 / 4$ in our calibration. For $\psi \geq .4$, therefore, the effect of $g_{t}$ on $y_{t}$ is larger than that on $y_{t}^{n}$, generating a positive output gap in the period of the shock. By contrast, for $\psi<.4$ a shock to $g_{t}$ generates on impact a negative output gap, because the fraction of consumers who react to the marginal utility shock is now quite small. As shown by the dashed-dotted lines in Figure 3, the output gap nevertheless turns positive in the following period because the shock is

\footnotetext{
${ }^{30}$ The operator $s d(\bullet)$ is an (undiscounted) unconditional standard deviation.

${ }^{31}$ Specifically, we consider a shock to $g_{t}$ and we assume that the source of this shock has a direct impact only on the marginal utility of consumption. Using the definitions of $g_{t}$ and $z_{t}$ in Appendix A, the shock is an innovation in the component of $g_{t}$ that is orthogonal to $z_{t}$. With rule-of-thumb consumers, a comparison of impulse responses to $\tilde{r}_{t}^{n}$ across different values of $\psi$ is no longer informative because the composition of $\tilde{r}_{t}^{n}$ changes, whereas its components $y_{t}^{n}, g_{t}, z_{t}$ do not.
} 
serially uncorrelated and hence its effect on $y_{t+1}^{n}$ is nil, but for low values of $\psi$ output itself is very persistent, and hence the increase in actual output in the previous period leads to a positive output gap this period. An interesting feature of optimal policy in the presence of lagged dynamics in the structural equations is that it acts preemptively - although inflation and the output gap both fall upon impact of the shock, the interest rate nevertheless rises in anticipation of the increase in inflation and the output gap the following period.

We then investigate the properties of the same set of interest rate rules as in the previous subsection, and for the same reasons as discussed there. Because all our results from the earlier analysis carry over to the case of rule-of-thumb consumers, we merely summarise these results here. First, the rule (24) comes very close to replicating the optimal plan for values of $\psi$ as low as .2, and according to this rule optimal policy is superinertial for all three values of $\psi$. Second, rules of the "a,c" type also show that feedback from the lagged interest rate greater than 1 is optimal for any value of $\psi$, although the welfare losses from more muted feedback become smaller with $\psi$. Again these rules suffer from the problem of extreme sensitivity of the feedback coefficients with respect to $\psi{ }^{32}$ Third, the "Taylor FD" rule performs fairly well for all values of $\psi$, although the relatively strong response to the output gap ( $V[x]$ is lower than under the optimal plan and any other rule) is costly in terms of interest rate variability. Fourth, the price level rule (26) is again very similar to the "a,c=1" rule, and suffers again from $a$ being very sensitive to changes in $\psi$.

\section{Robustness Analysis}

In this section we consider the robustness of our results along two dimensions. In the first subsection, we examine the implications from choosing alternative values for several of the parameters calibrated in section 3.1. In the second subsection we examine the robustness of our results when we allow for the presence of inefficient supply shocks that cause a tradeoff between output gap and inflation stabilisation. Since these shocks affect only the model's AS equation, we consider their policy implications only in the presence of rule-of-thumb price setters.

\footnotetext{
${ }^{32}$ While the rule (24) seems to suffer now from the same sensitivity problem (see the coefficients for $\psi=.6$ ), it should be noted that there exists a local minimum at $a=.313, b=.218, c_{1}+c_{2}=1.078$ for which $\hat{W}^{c}$ is .0003 higher than under the rule presented in Table 3. Thus a rule of the form (24) seems to be reasonably robust.
} 


\subsection{Alternative Parameter Values}

We consider three departures from the calibration described in section 3.1. For each alternative, results for those rules that exhibited the most desirable welfare properties under our base case calibration are shown in Table 4 (rule-of-thumb price setting) and Table 5 (rule-of-thumb consumption).

$\lambda_{r}=.077$. The weight $\lambda_{r}$ on interest rate variability chosen previously is based on the calculations in Rotemberg and Woodford (1997). Their value of $\lambda_{r}$ is in fact an approximation to a nonlinear constraint, namely the zero lower bound on nominal interest rates. Moreover, it reflects the large welfare costs of steady-state inflation in their model, and the fact that steady-state inflation must increase for sufficiently high interest rate variability in order to avoid the zero lower bound. Either of these two components may be poorly approximated, either because welfare costs of steady-state inflation are not as high (e.g. due to indexation among at least some price setters), or because the costs of being occasionally unable to lower nominal rates further are relatively minor. The extremely low interest rate variability, by historical standards, in all the cases presented in Tables 2 and 3 may suggest that .236 is too high a value for $\lambda_{r}$. Thus, we consider $\lambda_{r}=.077$, roughly $1 / 3$ of its previous value, and the implied weight on welfare losses resulting from interest rate variability solely due to monetary transactions frictions, as calibrated by Woodford (1999a).

Analysing the effects of changing $\lambda_{r}$ is relatively straightforward because it is only the weights in the welfare objective that change, not the structural equations. In particular, the trade-off now favours stabilisation of $\pi_{t}$ and $x_{t}$, and as a consequence their relative variances decline substantially. The coefficients on $\pi_{t}$ and $\Delta x_{t}$ in the rule that implements the optimal plan become larger (see Appendix C), while the coefficients on lagged interest rates are invariant to the change in $\lambda_{r}$. In particular, superinertial policy is still optimal, despite putting much lower weight on interest rate stabilisation. Other attributes of the various rules also continue to be present. For instance, as the degree of rule-of-thumb behaviour increases, the coefficients in the "a,b,c1,c2" rule remain relatively stable, whereas those in the "a,c" and price level rules are more variable, while still achieving nearly the same welfare levels. Finally, notice that by allowing greater variability in $r_{t}, V\left[\Delta y_{t}\right]$ is much lower across all values of $\psi$.

$\sigma=\omega=1$. A notable feature of our baseline calibration is the comparatively high values of the elasticities of intertemporal substitution and of labour supply, as represented by low values for 
$\sigma$ and $\omega$. Most studies of household behaviour, for example, find much smaller values for both of these elasticities. We therefore consider the case, popular in the real business cycle literature, of logarithmic utility, i.e. $\sigma=\omega=1$. All other parameters (including $\lambda_{r}$ ) are kept at their baseline values. However, these alternative values for $\sigma$ and $\omega$ lead to higher $\kappa, \lambda_{x}$ and $\lambda_{\Delta y}$.

Again, superinertial policy is desirable, but the most striking feature of the results in this case, as shown in Tables 4 and 5, are that the coefficients of all of the rules are much more stable across $\lambda$ and $\psi$. Comparing across the rules, the price level rule now performs relatively better, while the first-differenced Taylor rule is worse. In terms of the statistics, the increase in $\sigma$ reduces the impact of shocks to $\tilde{r}_{t}^{n}$, and far outweighs the increases in variability incited by a larger $\kappa$, resulting in the end in much lower variances for all of the endogenous variables. Under rule-of-thumb consumption, one interesting aspect of changing $\sigma$ and $\omega$ is that changes in the variance of $\tilde{r}_{t}^{n}$ are no longer monotonic with respect to $\psi$ (compare to Figure 2 ). In particular, $s d\left(\tilde{r}_{t}^{n}\right)$ reaches a minimum at $\psi=.6$. Moreover, for $\psi=.2, \operatorname{sd}\left(\tilde{r}_{t}^{n}\right) / \tilde{\sigma}$ is lower than for $\psi=1$, but higher than for $\psi=.6$. This last observation helps to explain the non-monotonicity of outcomes displayed in Table 5.

$\rho_{r}=.35$. We make one final departure from our baseline calibration by allowing for serial correlation in the exogenous shocks. We assume that $r^{n}$ and its components are first-order autoregressive processes, with serial correlation $\rho_{r}=.35$. We choose this particular value because, as discussed in Woodford (1999b), this value for $\rho_{r}$ implies in our model (which is identical to his model when $\lambda=\psi=1$ ) a degree of concern for reduction of interest rate variability similar to that obtained in the estimated model of Rotemberg and Woodford.

Turning again to Tables 4 and 5, note that this configuration of parameters is the same as those used by Woodford (1999b), and thus direct comparisons can be made to his results. For instance, Woodford reports the same values for $a$ and $c$ in the "a,c" rule. ${ }^{33}$ It is clear, however, that, as with the base case calibration, the coefficients in this rule change significantly with $\lambda$ and $\psi$. The performance of other rules is also similar to the base case: while the higher value of $\rho_{r}$ makes it more difficult to stabilise the economy, similar conclusions are reached about optimal policy rules. ${ }^{34}$

\footnotetext{
${ }^{33}$ Actually, Woodford reports a value for $a$ of 46.1 , compared to 46.366 in Table 4, which is accounted for by small differences (to the fourth decimal place) in our respective calibrations.

${ }^{34}$ Notice that the "a,b,c1,c2" rule is invariant to changes in $\rho_{r}$ for $\lambda=\psi=1$ (recall that optimal policy is independent of the processes for the shocks). The sensitivity of this rule's coefficients as $\psi$ changes, while more pronounced here than in section 3.2, is again somewhat misleading. As before, for $\psi=.6$, a rule with coeffcients similar to those obtained under other values of $\psi$ leads to trivial welfare loss.
} 


\subsection{Inefficient Supply Shocks}

An important assumption underlying the model presented in section 2 is that fluctuations in the natural rate $y_{t}^{n}$ are identical with fluctuations in the efficient level of output, that is, the level of output that would obtain absent any frictions, not just those associated with price setting. As a consequence, there exists no tradeoff between inflation stabilisation and stabilisation of output around its efficient level. However, much of the literature on stabilisation policy is concerned with optimal policy responses in the presence of such tradeoffs. In this subsection, we maintain the assumption that the steady-state level of output is efficient, but we now consider disturbances, such as variation in the degree of market power by firms, which may cause fluctuations in the natural rate to be inefficient. To this end, we define the output gap as the difference between $y_{t}$ and the efficient level of output $y_{t}^{e}$ (both expressed as percent deviations from steady state). The AS equation (12) is then given by

$$
\pi_{t}=\tilde{\kappa} x_{t}+\gamma^{b} \pi_{t-1}+\gamma^{f} E_{t} \pi_{t+1}+u_{t}
$$

where $x_{t} \equiv y_{t}-y_{t}^{e}$ and $u_{t} \equiv \tilde{\kappa}\left(y_{t}^{e}-y_{t}^{n}\right)$. Clarida et al. (1999), for example, analyze the implications of the presence of what they label "cost-push shocks" $u_{t}$ for monetary policy. ${ }^{35}$ Since it is this definition of $x_{t}$ that enters the objectives discussed in section 2 , the case of an inefficient natural rate of output implies the existence of a tradeoff between inflation and output gap stabilisation. However, the relative weights in the objective do not change (see Woodford (1999a)). With this change in the definition of $x_{t}$, the IS equation expressed in terms of the output gap becomes

$$
x_{t}=E_{t} x_{t+1}+\sigma^{-1} E_{t}\left[r_{t}-r_{t}^{n}-\pi_{t+1}\right]
$$

where it is now $y_{t}^{e}$, not $y_{t}^{n}$, that enters $r_{t}^{n}$.

To characterise optimal monetary policy in an economy with inefficient supply shocks, we must choose both the standard deviation of $u_{t}$ (denoted by $\tau_{u}$ ) and the correlation between $u_{t}$ and $r_{t}^{n}$. Unfortunately, there does not exist any empirical evidence on these parameters from an estimated model consistent with our structural equations. Thus, as an example, we set $\tau_{u}$ equal to .41. This value is obtained by again using Rotemberg and Woodford's (1997) estimation results, but making

\footnotetext{
${ }^{35}$ In recent independent work, Steinsson (2000) also considers the effects of inefficient supply shocks in a related model. However, there are important differences in our approaches. For example, Steinsson does not allow for shocks to the natural rate of interest, nor does he account for interest rate stabilization, which plays an important role in our results.
} 
the assumption that all variation in the natural rate of output is inefficient. ${ }^{36}$ We set the correlation between the shocks to zero, consistent with the interpretation of $u_{t}$ as representing shocks to firms' desired markups that are uncorrelated with the efficient rate of output or shocks to the marginal utility of consumption. ${ }^{37}$ We furthermore assume that $u_{t}$ is serially uncorrelated.

We follow the previous subsection by considering a similar subset of rules, with results reported in Table 6. In addition, we also examine an optimised version of (25), which is shown on the lines labelled "a,b,c" in the table. One obvious effect of introducing an inefficient supply shock is that it becomes more difficult to stabilise the economy and welfare falls ( $\hat{W}^{p}$ increases). This can be seen by examining the statistics under $\lambda=\psi=1$ for the "a,b,c1,c2" rule (which implements the optimal plan in this case as well; see above). Regarding implications for policy rules, one clear consequence of introducing $u_{t}$ is that rule coefficients are now fairly stable with respect to $\lambda$. Moreover, superinertial policy remains desirable. This result is of particular interest because policy is now concerned with more than influencing expectations of future real interest rates to alter the behaviour of $x_{t}$, and consequently $\pi_{t}$. It must also take into account shocks that affect $\pi_{t}$ directly.

In addition, there are two interesting pairwise comparisons to be made among the rules. First, the optimal coefficients in the "a,b,c" rule are much more robust than those in the "a,c" rule, and welfare gains can be achieved by allowing a direct response to $x_{t}$ due to the trade-off that now exists between $V\left[x_{t}\right]$ and $V\left[\pi_{t}\right] .{ }^{38}$ Second, the "a,b,c" rule coefficients are very similar to those in the "Taylor FD" rule across all values of $\lambda$, and both of these rules outperform the "a,b,c1,c2" rule for low values of $\lambda$. Thus, unlike in the case without inefficient supply shocks, the form of rule that is optimal in the absence of rule-of-thumb price setting is less attractive when, in contrast, the prevalence of such behaviour is significant.

\section{Conclusions}

In this paper we investigate the implications for monetary policy of agents occasionally relying upon a rule of thumb when making consumption and pricing decisions. We find that this type

\footnotetext{
${ }^{36}$ Thus, the chosen value provides an upper bound for this parameter, whereas our previous results were obtained by implicitly assuming that $\tau_{u}$ was at its lower bound of zero. See Giannoni (2000).

${ }^{37}$ The results reported in this section remain qualitatively unchanged when we allow $u_{t}$ to be positively or negatively correlated with $r_{t}^{n}$.

${ }^{38}$ This advantage in responding to $x_{t}$ was precisely the reason for considering a rule of this form in this case.
} 
of behaviour creates endogenous persistence in the processes for output and inflation; changes the dynamic responses of these variables to shocks; and alters the welfare function that policymakers seek to optimise.

In the face of rule-of-thumb price setting, the implications for monetary policy turn out to be minimal, at least in terms of how interest rates should move in response to shocks. By contrast, the path that interest rates should take following a shock is more sensitive to the degree of rule-ofthumb consumption behaviour present in the economy. Our most striking finding, across all model specifications that we consider, is that highly inertial policy is desirable, supporting and extending the same conclusion reached by Woodford in a purely optimising model. We also find that two rules in particular are robust in terms of welfare outcomes achieved and stability of coefficients. The first is the rule that implements the optimal plan when agents are always acting optimally. This rule requires that the current interest rate be set in response to its level in the past two periods, the current inflation rate and the change in the output gap. The second is a first-difference version of Taylor's rule.

Further work is required to show that the type of rules of thumb we consider are good approximations to actual decision making behaviour on the part of consumers and firms. Still, as we argued above, our model equations appear to be roughly consistent with different specifications of behaviour and preferences that have appeared in the literature so far. 


\section{A Log-linear Approximations}

\section{A.1 Derivation of Equations (5) and (12)}

As discussed in the text, we assume that asset markets are complete, and that households insure themselves against all idiosyncratic risks. Let $A_{t}^{i}$ denote the value of household $i$ 's assets at the beginning of period $t$, measured in units of the numeraire, and let $Q_{t, \tau}$ denote the stochastic discount factor with which households price in period $t$ nominal state-contingent payoffs in period $\tau$. Household $i$ 's budget constraint can then be written as

$$
E_{t}\left[Q_{t, t+1} A_{t+1}^{i}\right]=A_{t}^{i}+P_{t}\left(Y_{t}-C_{t}^{i}\right)+T_{t}
$$

Because of insurance against idiosyncratic income risk, each household's income (in units of consumption) is equal to aggregate income $Y_{t}$. Moreover, transfers $T_{t}$ are in place that offset the wealth effects of different choices between optimising and rule-of-thumb consumers. Although these are different across households depending on whether the household chooses current consumption optimally or according to the rule of thumb, each individual household views these transfers as exogenous, and hence no household index is attached to the transfer.

Assuming that a riskless nominal one-period bond exists, its gross rate of return $R_{t}$ between periods $t$ and $t+1$ is given by $R_{t}=\left(E_{t} Q_{t, t+1}\right)^{-1}$. Optimal choice of consumption is then characterised by the usual Euler equation

$$
\frac{u_{c}\left(C_{t}^{i} ; \xi_{t}\right)}{P_{t}}=\beta R_{t} E_{t}\left[\frac{u_{c}\left(C_{t+1}^{i} ; \xi_{t+1}\right)}{P_{t+1}}\right]
$$

Because the consumption choices of optimising households are identical, $C_{t}^{i}$ in (30) can be replaced by $C_{t}^{o}$.

In deriving (5) and (12) we take first-order Taylor-series expansions of the exact non-linear equilibrium conditions. If $\|\xi\|$ is a measure of the magnitude of fluctuations of the process $\left\{\xi_{t}\right\}$, the expansions in this subsection are accurate up to a remainder of size $\mathcal{O}\left(\|\xi\|^{2}\right)$, which we omit from the equations. For ease of exposition, we assume that the steady-state level of output is at its efficient level $Y^{*}$, characterised in our model by

$$
\frac{v_{y}\left(Y^{*} ; 0\right)}{u_{c}\left(Y^{*} ; 0\right)}=1
$$

and all Taylor series expansions are taken around $Y^{*}$. This assumption does not affect the results presented in this article. For a generalisation of the analysis to the case in which the steady-state 
output level is inefficient, see Woodford (1999a). Moreover, all expansions are developed around a zero inflation steady state, and we assume that the steady state value of $\xi_{t}$ is zero as well. A log-linear approximation of (30) around this steady state can then be written as

$$
-\sigma\left(c_{t}^{o}-g_{t}\right)=r_{t}-E_{t} \pi_{t+1}-\sigma E_{t}\left(c_{t+1}^{o}-g_{t+1}\right)
$$

where

$$
c_{t}^{o} \equiv \log \left(\frac{C_{t}^{o}}{Y^{*}}\right), \sigma \equiv-\frac{u_{c c}\left(Y^{*} ; 0\right) Y^{*}}{u_{c}\left(Y^{*} ; 0\right)}, g_{t} \equiv-\frac{u_{c \xi}\left(Y^{*} ; 0\right)}{u_{c c}\left(Y^{*} ; 0\right) Y^{*}} \xi_{t}
$$

and $r_{t} \equiv \log R_{t}-\log \beta^{-1}$, where $\beta^{-1}$ is the steady-state gross real interest rate. Market clearing requires that $C_{t} \equiv \psi C_{t}^{o}+(1-\psi) C_{t}^{r}$ equals $Y_{t}$, and hence the rule of thumb (1) implies that $C_{t}^{r}=$ $Y_{t-1}$. Solving for $C_{t}^{o}$ and taking logs, we obtain $c_{t}^{o}=\psi^{-1}\left(y_{t}-(1-\psi) y_{t-1}\right)$, where $y_{t} \equiv \log \left(Y_{t} / Y^{*}\right)$. Substituting for $c_{t}^{o}$ in (32) and rearranging yields (5).

In deriving (12) we assume that all households are able to solve the problem (30), so that $C_{t}^{o}=C_{t}=Y_{t}$. The first step in deriving (12) is to take the first-order condition of (11) with respect to $p_{t}^{o}$ and approximate it around the same steady state as before:

$$
E_{t} \sum_{j=0}^{\infty}(\alpha \beta)^{j}\left\{-\sigma\left(y_{t+j}-g_{t+j}\right)+\hat{p}_{t}^{o}-\sum_{k=1}^{j} \pi_{t+k}-\omega\left[y_{t+j}-z_{t+j}-\theta\left(\hat{p}_{t}^{o}-\sum_{k=1}^{j} \pi_{t+k}\right)\right]\right\}=0
$$

where

$$
\hat{p}_{t}^{o} \equiv \log \left(\frac{p_{t}^{o}}{P_{t}}\right), \omega \equiv \frac{v_{y y}\left(Y^{*} ; 0\right) Y^{*}}{v_{y}\left(Y^{*} ; 0\right)}, \text { and } z_{t} \equiv-\frac{v_{y \xi}\left(Y^{*} ; 0\right)}{v_{y y}\left(Y^{*} ; 0\right) Y^{*}} \xi_{t}
$$

Solving (33) for $\hat{p}_{t}^{o}$ yields

$$
\hat{p}_{t}^{o}=(1-\alpha \beta) E_{t} \sum_{j=0}^{\infty}(\alpha \beta)^{j}\left[\frac{\sigma+\omega}{1+\omega \theta}\left(y_{t}-y_{t}^{n}\right)+\sum_{k=1}^{j} \pi_{t+k}\right]
$$

where $y_{t}^{n} \equiv(\sigma+\omega)^{-1}\left(\sigma g_{t}+\omega z_{t}\right)$ is the "natural rate of output", i.e. the level of output that would obtain if all prices were flexible.

Log-linearising equation (10) and the price indices

$$
P_{t}^{*}=\left[\lambda\left(p_{t}^{o}\right)^{1-\theta}+(1-\lambda)\left(p_{t}^{r}\right)^{1-\theta}\right]^{\frac{1}{1-\theta}}
$$

and

$$
P_{t}=\left[\alpha P_{t-1}^{1-\theta}+(1-\alpha)\left(P_{t}^{*}\right)^{1-\theta}\right]^{\frac{1}{1-\theta}}
$$


yields respectively

$$
\begin{aligned}
\hat{p}_{t}^{r} & =\hat{p}_{t-1}^{*}+\pi_{t-1}-\pi_{t} \\
\hat{p}_{t}^{*} & =\lambda \hat{p}_{t}^{o}+(1-\lambda) \hat{p}_{t}^{r} \\
\hat{p}_{t}^{*} & =\frac{\alpha}{1-\alpha} \pi_{t}
\end{aligned}
$$

where $\hat{p}_{t}^{r} \equiv \log \left(p_{t}^{r} / P_{t}\right)$, and $\hat{p}_{t}^{*} \equiv \log \left(P_{t}^{*} / P_{t}\right)$. Substituting (37) and (39) into (38), we obtain

$$
\hat{p}_{t}^{o}=\frac{1-\lambda(1-\alpha)}{\lambda(1-\alpha)} \pi_{t}-\frac{1-\lambda}{\lambda(1-\alpha)} \pi_{t-1}
$$

Furthermore, the double sum in (34) can be simplified as

$$
\sum_{j=0}^{\infty}(\alpha \beta)^{j} \sum_{k=1}^{j} \pi_{t+k}=(1-\alpha \beta)^{-1}\left[\sum_{j=0}^{\infty}(\alpha \beta)^{j} \pi_{t+j}-\pi_{t}\right]
$$

Substituting (40) and (41) into (34), rearranging, and quasi-differencing the resulting expression, we obtain (12), where

$$
\begin{aligned}
\tilde{\kappa} & \equiv \frac{(1-\alpha)(1-\alpha \beta)}{\alpha+(1-\lambda)(1-\alpha(1-\beta))} \cdot \frac{\lambda(\sigma+\omega)}{1+\omega \theta} \\
\gamma^{b} & \equiv \frac{1-\lambda}{\alpha+(1-\lambda)(1-\alpha(1-\beta))} \\
\gamma^{f} & \equiv \frac{\alpha \beta}{\alpha+(1-\lambda)(1-\alpha(1-\beta))}
\end{aligned}
$$

For $\lambda=1, \gamma^{b}=0, \gamma^{f}=\beta$, and $\tilde{\kappa}$ reduces to

$$
\kappa \equiv \frac{(1-\alpha)(1-\alpha \beta)}{\alpha} \cdot \frac{\sigma+\omega}{1+\omega \theta}
$$

\section{A.2 The Representative Household's Welfare}

In this section we derive the second-order approximation (15) to the representative household's welfare (14), using methods discussed in more detail in Woodford (1999a). Specifically, we form a second-order Taylor series expansion of (14) around the steady state characterised by the efficient output level $Y^{*}$ defined in (31) and zero inflation. Hence, we form the approximation around the same steady state around which the model's exact equilibrium conditions have been log-linearised.

Let $U_{t} \equiv \psi u\left(C_{t}^{o} ; \xi_{t}\right)+(1-\psi) u\left(C_{t}^{r} ; \xi_{t}\right)-\int_{0}^{1} v\left(y_{t}(i) ; \xi_{t}\right) d i$. Using again that $C_{t}^{r}=Y_{t-1}$ and the expression (4) for $C_{t}^{o}$, the first two terms in $U_{t}$ can be approximated as

$$
\begin{aligned}
& \psi u\left(C_{t}^{o} ; \xi_{t}\right)+(1-\psi) u\left(C_{t}^{r} ; \xi_{t}\right) \\
& \quad=u_{c} Y^{*}\left[y_{t}+\frac{1}{2}(1-\sigma) y_{t}^{2}-\frac{1-\psi}{2 \psi} \sigma\left(y_{t}-y_{t-1}\right)^{2}+\sigma y_{t} g_{t}\right]+t . i . p .+\mathcal{O}\left(\|\xi\|^{3}\right)
\end{aligned}
$$


where the partial derivative $u_{c}$ is evaluated at $\left(Y^{*} ; 0\right)$, and $y_{t}, g_{t}$, and $\sigma$ are defined as in (32). The notation t.i.p. stands for terms that are independent of monetary policy, and the approximation is exact up to a remainder of order $\|\xi\|^{3}$.

Following the same steps as e.g. in Rotemberg and Woodford (1997), we obtain

$$
\begin{array}{rl}
\int_{0}^{1} & v\left(y_{t}(i) ; \xi_{t}\right) d i \\
& =v_{y} Y^{*}\left[y_{t}+\frac{1}{2}(1+\omega) y_{t}^{2}+\frac{1}{2}\left(\theta^{-1}+\omega\right) \operatorname{var}_{i}\left(\hat{y}_{t}(i)\right)-\omega y_{t} z_{t}\right]+\text { t.i.p. }+\mathcal{O}\left(\|\xi\|^{3}\right)
\end{array}
$$

where $z_{t}$ and $\omega$ are defined as in $(33), \hat{y}_{t}(i) \equiv \log \left(y_{t}(i) / Y^{*}\right)$, and $\operatorname{var}_{i}$ measures the variance of $\hat{y}_{t}(i)$ across $i$. Subtracting (43) from (42), and using from (31) that $u_{c}=v_{y}$, and from (3) that $\operatorname{var}_{i}\left(\hat{y}_{t}(i)\right)=\theta^{2} \operatorname{var}_{i}\left(\log p_{t}(i)\right)$, we obtain

$$
U_{t}=-\frac{Y^{*} u_{c}}{2}\left[(\sigma+\omega) x_{t}^{2}+\sigma \frac{1-\psi}{\psi}\left(y_{t}-y_{t-1}\right)^{2}+\theta(1+\omega \theta) \operatorname{var}_{i}\left(\log p_{t}(i)\right)\right]+\text { t.i.p. }+\mathcal{O}\left(\|\xi\|^{3}\right)
$$

Let $\bar{P}_{t} \equiv E_{i}\left[\log p_{t}(i)\right]$ and $\Delta_{t} \equiv \operatorname{var}_{i}\left(\log p_{t}(i)\right)$. Then

$$
\begin{aligned}
\Delta_{t} & =\operatorname{var}_{i}\left(\log p_{t}^{i}-\bar{P}_{t-1}\right) \\
& =E_{i}\left[\left(\log p_{t}(i)-\bar{P}_{t-1}\right)^{2}\right]-\left(E_{i}\left[\log p_{t}(i)-\bar{P}_{t-1}\right]\right)^{2} \\
& =\alpha \Delta_{t-1}+(1-\alpha) \lambda\left(\log p_{t}^{o}-\bar{P}_{t-1}\right)^{2}+(1-\alpha)(1-\lambda)\left(\log p_{t}^{r}-\bar{P}_{t-1}\right)^{2}-\left(\bar{P}_{t}-\bar{P}_{t-1}\right)^{2}
\end{aligned}
$$

We now wish to substitute for each of the squared terms in (45) in terms of inflation. First note that $\bar{P}_{t}=\log P_{t}+\mathcal{O}\left(\|\xi\|^{2}\right)$, so that $\bar{P}_{t}-\bar{P}_{t-1}=\pi_{t}+\mathcal{O}\left(\|\xi\|^{2}\right)$. Furthermore, taking logs on both sides of (36) and rearranging yields

$$
\log P_{t}^{*}-\log P_{t}=\frac{\alpha}{1-\alpha} \pi_{t}
$$

Taking logs on both sides of (10) yields

$$
\log p_{t}^{r}=\log P_{t}^{*}+\log P_{t-1}-\log P_{t-2}
$$

and, using (46),

$$
\log p_{t}^{r}-\log P_{t-1}=\frac{1}{1-\alpha} \pi_{t-1}
$$

Finally, taking logs on both sides of (35), rearranging, and substituting from (46) and (47), we obtain

$$
\log p_{t}^{o}-\log P_{t-1}=\frac{1}{\lambda(1-\alpha)} \pi_{t}-\frac{1-\lambda}{\lambda(1-\alpha)} \pi_{t-1}
$$


Substituting (48) and (49) into (45) then yields

$$
\begin{aligned}
\Delta_{t} & =\alpha \Delta_{t-1}+\frac{\alpha}{1-\alpha} \pi_{t}^{2}+\frac{1-\lambda}{\lambda(1-\alpha)}\left(\pi_{t}-\pi_{t-1}\right)^{2}+\mathcal{O}\left(\|\xi\|^{3}\right) \\
& =\alpha^{t+1} \Delta_{-1}+\sum_{s=0}^{t} \alpha^{t-s}\left[\frac{\alpha}{1-\alpha} \pi_{s}^{2}+\frac{1-\lambda}{\lambda(1-\alpha)}\left(\pi_{s}-\pi_{s-1}\right)^{2}\right]+\mathcal{O}\left(\|\xi\|^{3}\right)
\end{aligned}
$$

Since we consider evaluating policies adopted at time 0 , the term $\Delta_{-1}$ is treated as independent of the policy under consideration. Hence,

$$
\sum_{t=0}^{\infty} \beta^{t} \Delta_{t}=\frac{1}{1-\alpha \beta} \sum_{t=0}^{\infty} \beta^{t}\left[\frac{\alpha}{1-\alpha} \pi_{t}^{2}+\frac{1-\lambda}{\lambda(1-\alpha)}\left(\pi_{t}-\pi_{t-1}\right)^{2}\right]+\text { t.i.p. }+\mathcal{O}\left(\|\xi\|^{3}\right)
$$

Taking the discounted sum $\sum_{t=0}^{\infty} \beta^{t} U_{t}$ using (44) and (51), we obtain the loss functions presented in the text.

\section{B Calibration of Shock Processes}

In this appendix we present the calibration of the components $y_{t}^{n}, g_{t}$, and $z_{t}$ of the shock process $r_{t}^{n}$ as defined in (9). In appendix A.1 we defined

$$
y_{t}^{n} \equiv \frac{\sigma}{\sigma+\omega} g_{t}+\frac{\omega}{\sigma+\omega} z_{t}, g_{t} \equiv-\frac{u_{c \xi}\left(Y^{*} ; 0\right)}{u_{c c}\left(Y^{*} ; 0\right) Y^{*}} \xi_{t}, \text { and } z_{t} \equiv-\frac{v_{y \xi}\left(Y^{*} ; 0\right)}{v_{y y}\left(Y^{*} ; 0\right) Y^{*}} \xi_{t}
$$

We would like to model $g_{t}$ and $z_{t}$ as $\operatorname{AR}(1)$ processes

$$
\begin{aligned}
& g_{t}=\rho_{g} g_{t-1}+\epsilon_{t} \\
& z_{t}=\rho_{z} z_{t-1}+\eta_{t}
\end{aligned}
$$

where $\left[\epsilon_{t}, \eta_{t}\right]$ are i.i.d. mean zero disturbances with covariance matrix

$$
V \equiv\left[\begin{array}{cc}
\tau_{\epsilon}^{2} & \tau_{\epsilon \eta} \\
\tau_{\epsilon \eta} & \tau_{\eta}^{2}
\end{array}\right]
$$

Rotemberg and Woodford (1997) present empirical estimates of the shock processes $g_{t}$ and $y_{t}^{n}$ (and hence implicitly of $z_{t}$ ) based on their study of U.S. data for the period 1980-95. The standard deviations of their processes $E_{t-2} \hat{G}_{t}$ and $E_{t-2} \bar{Y}_{t}$, corresponding to $g_{t}$ and $z_{t}$ and expressed as percentages of steady-state output, are 29.46 and 11.72 respectively, while the first-order serial correlation of their processes is 0.92 and 0.68 . Furthermore, the two processes are highly negatively correlated with each other, with a correlation coefficient of -0.87 . However, $E_{t-2} \hat{G}_{t}$ and $E_{t-2} \bar{Y}_{t}$ 
are not simple $\mathrm{AR}(1)$ processes, but have a more complex dynamic structure. If we calibrated the matrix $V$ and the parameters $\rho_{g}$ and $\rho_{z}$ to reproduce the variances and first-order correlations of Rotemberg and Woodford's processes, the implied standard deviation and first-order serial correlation of $r_{t}^{n}$ would be different from our calibration in the text.

Instead, we would like to maintain that the standard deviation of $r_{t}^{n}$ is 3.72 , to facilitate comparison of our results with those of Woodford (1999b). For simplicity, we assume that $\rho_{g}=$ $\rho_{z}$, which implies that these coefficients are equal to $\rho_{r}$, which is 0 in the baseline calibration, and .35 in one of our alternative calibrations. From Rotemberg and Woodford's estimates we preserve the correlation between $g_{t}$ and $z_{t}$ of -.87. Given a value for $\rho_{r}$, our assumptions thus impose two restrictions on the three elements of $V$. To identify these three elements, we need one further restriction. For this we choose to maintain the relative magnitude among the variances and covariance between Rotemberg and Woodford's $E_{t-2} \hat{G}_{t}$ and $E_{t-2} \bar{Y}_{t}$, i.e. the covariance matrix of $g$ and $z$ implied by our choice of $V$ and $\rho_{r}$ is a scalar multiple of Rotemberg and Woodford's covariance matrix of $E_{t-2} \hat{G}_{t}$ and $E_{t-2} \bar{Y}_{t}$. For $\rho_{g}=\rho_{z}=0$, the elements of $V$ are then given by $\tau_{\epsilon}^{2}=33.52, \tau_{\eta}^{2}=5.31$, and $\tau_{\epsilon \eta}=-11.66$, whereas for $\rho_{g}=\rho_{z}=.35$ they are given by $\tau_{\epsilon}^{2}=69.61, \tau_{\eta}^{2}=11.02$, and $\tau_{\epsilon \eta}=-24.21$.

\section{Conditions Characterising the Optimal Plan}

With rule-of-thumb price setters, the objective is to minimise (15), where the period loss function is (18), with respect to the endogenous variables subject to the structural equations (6) and (12) holding at any point in time. Appending the term $\lambda_{r} r_{t}^{2}$ to $L_{t}$ for the reasons discussed in section 2 , and omitting terms independent of policy, the problem of choosing at time 0 an optimal plan for the endogenous variables $\left\{x_{t}, \pi_{t}, r_{t}\right\}$ can be stated as a Lagrangian

$$
E_{0}\left\{\sum_{t=0}^{\infty} \beta^{t}\left[L_{t}+2 \phi_{1, t}\left[x_{t}-x_{t+1}+\sigma^{-1}\left(r_{t}-r_{t}^{n}-\pi_{t+1}\right)\right]+2 \phi_{2, t}\left[\pi_{t}-\tilde{\kappa} x_{t}-\gamma^{b} \pi_{t-1}-\gamma^{f} \pi_{t+1}\right]\right]\right\}
$$

where

$$
L_{t} \equiv \pi_{t}^{2}+\lambda_{\Delta \pi}\left(\pi_{t}-\pi_{t-1}\right)^{2}+\lambda_{x} x_{t}^{2}+\lambda_{r} r_{t}^{2}
$$

The first-order conditions with respect to $\pi_{t}, x_{t}$, and $r_{t}$ are

$$
0=\left(1+(1+\beta) \lambda_{\Delta \pi}\right) \pi_{t}-\lambda_{\Delta \pi} \pi_{t-1}-\beta \lambda_{\Delta \pi} E_{t} \pi_{t+1}
$$




$$
\begin{aligned}
& -(\sigma \beta)^{-1} \phi_{1, t-1}-\beta \gamma^{b} E_{t} \phi_{2, t+1}+\phi_{2, t}-\beta^{-1} \gamma^{f} \phi_{2, t-1} \\
0= & \lambda_{x} x_{t}+\phi_{1, t}-\beta^{-1} \phi_{1, t-1}-\tilde{\kappa} \phi_{2, t} \\
0= & \sigma^{-1} \phi_{1, t}+\lambda_{r} r_{t}
\end{aligned}
$$

An optimal plan is defined as a bounded solution $\left\{\pi_{t}, x_{t}, r_{t}, \phi_{1, t}, \phi_{2, t}\right\}_{t=0}^{\infty}$ to the system of equations (6), (12), and (56)-(58) together with the initial condition that $\phi_{1,-1}=\phi_{2,-1}=0$.

By solving out for the multipliers from equations (56)-(58), we obtain the law of motion for the interest rate implicit in the optimal plan, i.e. the interest rate rule which would implement the optimal plan:

$$
\begin{aligned}
r_{t}= & \left(\sigma \lambda_{r}\left(1+\gamma^{b}\right)\right)^{-1}\left\{\tilde{\kappa}\left[\left(1+(1+\beta) \lambda_{\Delta \pi}\right) \pi_{t}-\lambda_{\Delta \pi} \pi_{t-1}-\beta \lambda_{\Delta \pi} E_{t} \pi_{t+1}\right]\right. \\
& \left.+\lambda_{x}\left[x_{t}-\beta^{-1} \gamma^{f} x_{t-1}-\beta \gamma^{b} E_{t} x_{t+1}\right]\right\} \\
& +\beta \gamma^{b} E_{t} r_{t+1}+\beta^{-1}\left(1+\gamma^{f}+\tilde{\kappa} \sigma^{-1}\right) r_{t-1}-\beta^{-2} \gamma^{f} r_{t-2}
\end{aligned}
$$

With rule-of-thumb consumers, the objective is to minimise (15), where the period loss function is (20), with respect to the endogenous variables subject to the structural equations (7) and (13) holding at any point in time. Again appending the term $\lambda_{r} r_{t}^{2}$ to $L_{t}$, the problem of choosing at time 0 an optimal plan for the endogenous variables $\left\{x_{t}, \pi_{t}, r_{t}\right\}$ can be stated as the Lagrangian

$$
E_{0}\left\{\sum_{t=0}^{\infty} \beta^{t}\left[L_{t}+2 \phi_{1, t}\left[x_{t}-(1-\delta) x_{t-1}-\delta x_{t+1}+\tilde{\sigma}^{-1}\left(r_{t}-r_{t}^{n}-\pi_{t+1}\right)\right]+2 \phi_{2, t}\left[\pi_{t}-\kappa x_{t}-\beta \pi_{t+1}\right]\right]\right\}
$$

where

$$
L_{t} \equiv \pi_{t}^{2}+\lambda_{x} x_{t}^{2}+\lambda_{\Delta y}\left(y_{t}-y_{t-1}\right)^{2}+\lambda_{r} r_{t}^{2}
$$

The first-order conditions with respect to $\pi_{t}, x_{t}$, and $r_{t}$ are

$$
\begin{aligned}
0= & \pi_{t}-(\tilde{\sigma} \beta)^{-1} \phi_{1, t-1}+\phi_{2, t}-\phi_{2, t-1} \\
0= & \lambda_{x} x_{t}+(1+\beta) \lambda_{\Delta y}\left(x_{t}+y_{t}^{n}\right)-\lambda_{\Delta y}\left(x_{t-1}+y_{t-1}^{n}\right)-\beta \lambda_{\Delta y} E_{t}\left[x_{t+1}+y_{t+1}^{n}\right] \\
& -\beta(1-\delta) E_{t} \phi_{1, t+1}+\phi_{1, t}-\beta^{-1} \delta \phi_{1, t-1}-\kappa \phi_{2, t} \\
0= & \tilde{\sigma}^{-1} \phi_{1, t}+\lambda_{r} r_{t}
\end{aligned}
$$

In this case, an optimal plan is defined as a bounded solution $\left\{\pi_{t}, x_{t}, r_{t}, \phi_{1, t}, \phi_{2, t}\right\}_{t=0}^{\infty}$ to the system of equations (7), (13), and (61)-(63) together with the initial condition that $\phi_{1,-1}=\phi_{2,-1}=0$. 
Again we can solve out for the multipliers from equations (61)-(63) to obtain the law of motion for the interest rate implicit in the optimal plan:

$$
\begin{aligned}
r_{t}= & \left(\tilde{\sigma} \lambda_{r}\right)^{-1}\left\{\kappa \pi_{t}+\lambda_{x}\left(x_{t}-x_{t-1}\right)+\lambda_{\Delta y}\left[(1+\beta) \Delta y_{t}-\Delta y_{t-1}-\beta\left(E_{t} y_{t+1}-E_{t-1} y_{t}\right)\right]\right\} \\
& +\beta(1-\delta)\left(E_{t} r_{t+1}-E_{t-1} r_{t}\right)+\left(1+\beta^{-1}\left(\delta+\kappa \tilde{\sigma}^{-1}\right)\right) r_{t-1}-\beta^{-1} \delta r_{t-2}
\end{aligned}
$$




\section{References}

[1] Amato, J.D. and T. Laubach, 2001a, Implications of habit formation for optimal monetary policy, Finance and Economics Discussion Series no. 2001-58, Federal Reserve Board.

[2] Amato, J.D. and T. Laubach, 2001b, Estimation and control of an optimisation-based model with sticky prices and wages, Journal of Economic Dynamics and Control, forthcoming.

[3] Blinder, A.S., 1994, On sticky prices: Academic theories meet the real world, in: N.G. Mankiw, ed., Monetary policy (University of Chicago Press, Chicago) 117-150.

[4] Calvo, G.A., 1983, Staggered prices in a utility-maximising framework, Journal of Monetary Economics 12, 383-398.

[5] Campbell, J.Y., A.W. Lo and A.C. MacKinlay, 1997, The econometrics of financial markets, Princeton University Press, Princeton.

[6] Christiano, L.J., M. Eichenbaum and C. Evans, 2001, Nominal rigidities and the dynamic effects of a shock to monetary policy, Federal Reserve Bank of Cleveland, working paper no. 01-07.

[7] Clarida, R., J. Gali and M. Gertler, 1999, The science of monetary policy: A New Keynesian perspective, Journal of Economic Literature 37, 1661-1707.

[8] Coenen, Günter, and Volker Wieland, 2000, A small estimated Euro area model with rational expectations and nominal rigidities, ECB working paper no. 30, European Central Bank.

[9] Deaton, A., 1992, Understanding consumption (Clarendon Press, Oxford).

[10] Dotsey, M., R.G. King and A.L. Wolman, 1999, State-dependent pricing and the general equilibrium dynamics of money and output, Quarterly Journal of Economics 114, 655-690.

[11] Dynan, K.E., 2000, Habit formation in consumer preferences: evidence from panel data, American Economic Review 90, 391-406.

[12] Fuhrer, J.C., 1997a, Comment, in: B.S. Bernanke and J.J. Rotemberg, eds., NBER Macroeconomics Annual (MIT Press, Cambridge) 346-355. 
[13] Fuhrer, J.C., 1997b, Towards a compact, empirically-verified rational expectations model for monetary policy analysis, Carnegie-Rochester Conference Series on Public Policy 47, 197-230.

[14] Fuhrer, J.C., 2000, Habit formation in consumption and its implications for monetary-policy models, American Economic Review 90, 367-390.

[15] Fuhrer, J.C., and G. Moore, 1995a, Inflation persistence, Quarterly Journal of Economics 110, $127-159$.

[16] Fuhrer, J.C., and G. Moore, 1995b, Monetary policy trade-offs and the correlation between nominal interest rates and real output, American Economic Review 85, 219-39.

[17] Gabaix, X. and D. Laibson, 2001, The 6D bias and the equity premium puzzle, manuscript, Harvard University.

[18] Gali, J., and M. Gertler, 1999, Inflation dynamics: A structural econometric analysis, Journal of Monetary Economics 44, 195-222.

[19] Gali, J., M. Gertler and J.D. Lopez-Salido, 2001, European inflation dynamics, European Economic Review 45, 1237-1270.

[20] Giannoni, M., 2000, Optimal interest-rate rules in a forward-looking model, and inflation stabilisation versus price-level stabilisation, manuscript, Federal Reserve Bank of New York.

[21] Giannoni, M., and M. Woodford, 2001, Optimal interest-rate rules, manuscript, Federal Reserve Bank of New York.

[22] Ireland, P.N., 1997, A small, structural, quarterly model for monetary policy evaluation, Carnegie-Rochester Conference Series on Public Policy 47, 83-108.

[23] Levin, A., V. Wieland and J.C. Williams, 1999, Robustness of simple monetary policy rules under model uncertainty, in: J.B. Taylor, ed., Monetary policy rules (University of Chicago Press, Chicago) 263-299.

[24] Mankiw, N.G. and R. Reis, 2001, Sticky information versus sticky prices: a proposal to replace the new Keynesian Phillips curve, NBER working paper no. 8290. 
[25] Mankiw, N.G., J.J. Rotemberg and L.H. Summers, 1985, Intertemporal substitution in macroeconomics, Quarterly Journal of Economics 100, 225-251.

[26] McCallum, B.T. and E. Nelson, 1999a, An optimising IS-LM specification for monetary policy and business cycle analysis, Journal of Money, Credit, and Banking 31, 296-316.

[27] McCallum, B.T. and E. Nelson, 1999b, Nominal income targeting in an open-economy optimising model, Journal of Monetary Eonomics 43, 553-578.

[28] Roberts, J.M., 1995, New Keynesian economics and the Phillips curve, Journal of Money, Credit, and Banking 27, 975-984.

[29] Roberts, J.M., 1997, Is inflation sticky?, Journal of Monetary Economics 39, 173-196.

[30] Rotemberg, J.J., 1982, Sticky prices in the United States, Journal of Political Economy 90, $1187-1211$.

[31] Rotemberg, J.J., and M. Woodford, 1997, An optimisation-based econometric framework for the evaluation of monetary policy, in: B.S. Bernanke and J.J. Rotemberg, eds., NBER macroeconomics annual (MIT Press, Cambridge) 297-346.

[32] Rotemberg, J.J., and M. Woodford, 1999, Interest-rate rules in an estimated sticky price model, in: J.B. Taylor, ed., Monetary policy rules (University of Chicago Press, Chicago) 57-119.

[33] Rudebusch, G.D., and L.E.O. Svensson, 1999, Policy rules for inflation targeting, in: J.B. Taylor, ed., Monetary policy rules (University of Chicago Press, Chicago) 203-246.

[34] Sbordone, A.M., 2001, Prices and unit labor costs: A new test of price stickiness, Journal of Monetary Economics, forthcoming.

[35] Steinsson, J., 2000, Optimal monetary policy in an economy with inflation persistence, manuscript, Princeton University.

[36] Taylor, J.B., 1979, Estimation and control of a macroeconomic model with rational expectations, Econometrica 47, 1267-1286.

[37] Taylor, J.B., 1993, Discretion versus policy rules in practice, Carnegie-Rochester Conference Series on Public Policy 39, 195-214. 
[38] Taylor, J.B., 1999a, Introduction, in: J.B. Taylor, ed., Monetary policy rules (University of Chicago Press, Chicago) 1-14.

[39] Taylor, J.B., 1999b, ed., Monetary policy rules, University of Chicago Press, Chicago.

[40] Taylor, J.B., 1999c, Staggered price and wage setting in macroeconomics, in: J.B. Taylor and M. Woodford, eds., Handbook of macroeconomics (Elsevier Science, Amsterdam) 1009-1050.

[41] Vestin, D., 2000, Price level targeting versus inflation targeting in a forward looking model, Sveriges Riksbank working paper no. 106.

[42] Woodford, M., 1996, Control of the public debt: A requirement for price stability?, NBER working paper no. 5684 .

[43] Woodford, M., 1999a, Inflation stabilisation and welfare, manuscript, Princeton University.

[44] Woodford, M., 1999b, Optimal monetary policy inertia, NBER working paper no. 7261.

[45] Zbaracki, M.J., M. Ritson, D. Levy, S. Dutta and M. Bergen, 2000, The managerial and customer costs of price adjustment: direct evidence from industrial markets, manuscript, Emory University. 
Table 1: Base Case Calibration

\begin{tabular}{|c|c|}
\hline \multicolumn{2}{|c|}{ Structural Parameters } \\
\hline$\alpha$ & $0.66 /$ quarter \\
$\beta$ & $0.99 /$ quarter \\
$\sigma$ & 0.157 \\
$\omega$ & 0.473 \\
$\theta$ & 7.88 \\
\hline \multicolumn{2}{|c|}{ Interest-Rate Weight } \\
\hline$\lambda_{r}$ & 0.236 \\
\hline \multicolumn{2}{|c|}{ Shock Process } \\
\hline $\operatorname{sd}\left(r^{n}\right)$ & 0.93 percent/quarter \\
$\rho_{r}$ & 0 \\
\hline
\end{tabular}


Table 2: Optimal Policy and Rules under Rule-of-Thumb Price Setting Base Case Calibration

\begin{tabular}{|c|c|c|c|c|c|c|c|c|}
\hline & $\mathrm{a}$ & b & $\mathrm{c}$ & $V\left[\pi_{t}\right]$ & $V\left[\Delta \pi_{t}\right]$ & $V\left[x_{t}\right]$ & $V\left[r_{t}\right]$ & $W^{p}$ \\
\hline \multicolumn{9}{|c|}{$\lambda=1$} \\
\hline Opt plan & & & 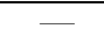 & 0.070 & 0.089 & 9.755 & 0.986 & 0.774 \\
\hline $\mathrm{a}, \mathrm{b}, \mathrm{c} 1, \mathrm{c} 2$ & 0.642 & 0.326 & 1.153 & 0.070 & 0.089 & 9.755 & 0.986 & 0.774 \\
\hline $\mathrm{a}, \mathrm{c}$ & 62.251 & 0.000 & 17.420 & 0.073 & 0.088 & 9.708 & 0.986 & 0.775 \\
\hline $\mathrm{a}, \mathrm{c}=1$ & 874 & 0.000 & 1.000 & 0.049 & 0.130 & 10.861 & 1.241 & 0.867 \\
\hline $\mathrm{a}, \mathrm{c}=0.5$ & 4.941 & 0.000 & 0.500 & 0.065 & 0.162 & 11.260 & 1.550 & 0.975 \\
\hline $\mathrm{a}, \mathrm{c}=0.2$ & 4.482 & 0.000 & 0.200 & 0.092 & 0.199 & 12.044 & 1.848 & 1.110 \\
\hline$a, b$ & 4.039 & 0.003 & 0.000 & 0.122 & 0.242 & 13.417 & 2.011 & 1.244 \\
\hline Taylor & 1.500 & 0.500 & 0.000 & 0.078 & 0.154 & 8.562 & 3.538 & 1.326 \\
\hline Taylor FD & 1.500 & 0.500 & 1.000 & 0.036 & 0.070 & 7.358 & 1.878 & 0.835 \\
\hline P-level & 9.648 & -0.197 & 0.000 & 0.044 & 0.123 & 10.678 & 1.224 & 0.849 \\
\hline \multicolumn{9}{|c|}{$\lambda=0.6$} \\
\hline Opt plan & & & & 0.039 & 0.025 & 10.177 & 1.081 & 0.810 \\
\hline $\mathrm{a}, \mathrm{b}, \mathrm{c} 1, \mathrm{c} 2$ & 0.874 & 0.339 & 1.172 & 0.039 & 0.025 & 10.179 & 1.081 & 0.810 \\
\hline $\mathrm{a}, \mathrm{c}$ & 23.595 & 0.000 & 3.911 & 0.022 & 0.023 & 10.987 & 1.094 & 0.835 \\
\hline $\mathrm{a}, \mathrm{c}=1$ & 11.119 & 0.000 & 1.000 & 0.010 & 0.023 & 10.978 & 1.293 & 0.868 \\
\hline $\mathrm{a}, \mathrm{c}=0.5$ & 9.932 & 0.000 & 0.500 & 0.012 & 0.025 & 10.962 & 1.459 & 0.911 \\
\hline $\mathrm{a}, \mathrm{c}=0.2$ & 384 & 0.000 & 0.200 & 0.016 & 0.028 & 1.128 & 1.596 & 0.959 \\
\hline & & -0.468 & 0.000 & 0.014 & 0.026 & 11.092 & 1.550 & 0.941 \\
\hline Taylor & 500 & 0.500 & 0.000 & 0.037 & 0.035 & 9.604 & 3.226 & 1.298 \\
\hline Taylor FD & 1.500 & 0.500 & 1.000 & 0.016 & 0.016 & 7.876 & 1.887 & 0.859 \\
\hline P-level & 10.162 & 0.030 & 0.000 & 0.010 & 0.023 & 10.941 & 1.294 & 0.867 \\
\hline \multicolumn{9}{|c|}{$\lambda=0.2$} \\
\hline Opt plan & - & 一 & - & 0.007 & 0.002 & 11.079 & 1.177 & 0.832 \\
\hline $\mathrm{a}, \mathrm{b}, \mathrm{c} 1, \mathrm{c} 2$ & 0.530 & 0.337 & 1.034 & 0.007 & 0.002 & 11.087 & 1.188 & 0.835 \\
\hline $\mathrm{a}, \mathrm{c}$ & 34.562 & 0.000 & 0.652 & 0.001 & 0.001 & 11.453 & 1.289 & 0.867 \\
\hline $\mathrm{a}, \mathrm{c}=1$ & 6.404 & 0.000 & 1.000 & 0.001 & 0.001 & 1.597 & 1.275 & 0.870 \\
\hline $\mathrm{a}, \mathrm{c}=0.5$ & 33.964 & 0.000 & 0.500 & 0.001 & 0.001 & 11.417 & 1.300 & 0.868 \\
\hline $\mathrm{a}, \mathrm{c}=0.2$ & 32.963 & 0.000 & 0.200 & 0.001 & 0.002 & 11.467 & 1.325 & 0.877 \\
\hline$a, b$ & 48.484 & -0.156 & 0.000 & 0.001 & 0.002 & 11.485 & 1.325 & 0.878 \\
\hline Taylor & 1.500 & 0.500 & 0.000 & 0.016 & 0.002 & 10.552 & 2.887 & 1.222 \\
\hline Taylor FD & 1.500 & 0.500 & 1.000 & 0.004 & 0.001 & 8.459 & 1.893 & 0.867 \\
\hline P-level & 26.203 & 0.102 & 0.000 & 0.001 & 0.001 & 11.329 & 1.257 & 0.854 \\
\hline
\end{tabular}

Notes: The table shows the level of welfare $\hat{W}^{p}$ and its component discounted variances achieved under the optimal plan (Opt plan) and various rules. Rules listed under the optimal plan correspond to, in order, rule (24); rule (25) with $b=0, b=0$ and $\mathrm{c}=1, \mathrm{~b}=0$ and $\mathrm{c}=0.5$, or $\mathrm{b}=0$ and $\mathrm{c}=0.2$; rule $(25)$ with $\mathrm{c}=0, \mathrm{a}=1.5 \mathrm{~b}=0.5$ and $\mathrm{c}=0$, or $\mathrm{a}=1.5, \mathrm{~b}=0.5$ and $\mathrm{c}=1$; rule (26). Except where stated, rule coefficients are found optimally. Inflation and the interest rate are expressed in annualised percentages, the output gap in percentages. 
Table 3: Optimal Policy and Rules under Rule-of-Thumb Consumption

\section{Base Case Calibration}

\begin{tabular}{|c|c|c|c|c|c|c|c|c|}
\hline & $\mathrm{a}$ & $\mathrm{b}$ & $\mathrm{c}$ & $V\left[\pi_{t}\right]$ & $V\left[\Delta y_{t}\right]$ & $V\left[x_{t}\right]$ & $V\left[r_{t}\right]$ & $\hat{W}^{c}$ \\
\hline \multicolumn{9}{|c|}{$\psi=1$} \\
\hline Opt plan & 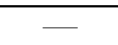 & & & 0.070 & 23.722 & 9.755 & 0.986 & 0.774 \\
\hline $\mathrm{a}, \mathrm{b}, \mathrm{c} 1, \mathrm{c} 2$ & 0.642 & 0.326 & 1.153 & 0.070 & 23.722 & 9.755 & 0.986 & 0.774 \\
\hline $\mathrm{a}, \mathrm{c}$ & 62.251 & 0.000 & 17.420 & 0.073 & 23.574 & 9.708 & 0.986 & 0.775 \\
\hline $\mathrm{a}, \mathrm{c}=1$ & 5.874 & 0.000 & 1.000 & 0.049 & 25.290 & 10.861 & 1.241 & 0.867 \\
\hline $\mathrm{a}, \mathrm{c}=0.5$ & 4.941 & 0.000 & 0.500 & 0.065 & 24.708 & 11.260 & 1.550 & 0.975 \\
\hline $\mathrm{a}, \mathrm{c}=0.2$ & 4.482 & 0.000 & 0.200 & 0.092 & 24.469 & 12.044 & 1.848 & 1.110 \\
\hline $\mathrm{a}, \mathrm{b}$ & 4.039 & 0.003 & 0.000 & 0.122 & 25.357 & 13.417 & 2.011 & 1.244 \\
\hline Taylor & 1.500 & 0.500 & 0.000 & 0.078 & 16.253 & 8.562 & 3.538 & 1.326 \\
\hline Taylor FD & 1.500 & 0.500 & 1.000 & 0.036 & 18.410 & 7.358 & 1.878 & 0.835 \\
\hline P-level & 9.648 & -0.197 & 0.000 & 0.044 & 26.148 & 10.678 & 1.224 & 0.849 \\
\hline \multicolumn{9}{|c|}{$\psi=0.6$} \\
\hline Opt plan & - & & & 0.044 & 8.403 & 4.954 & 0.458 & 0.459 \\
\hline $\mathrm{a}, \mathrm{b}, \mathrm{c} 1, \mathrm{c} 2$ & 37.912 & -0.939 & 10.769 & 0.044 & 8.506 & 4.990 & 0.454 & 0.461 \\
\hline $\mathrm{a}, \mathrm{c}$ & 7.371 & 0.000 & 2.868 & 0.044 & 8.570 & 4.996 & 0.453 & 0.461 \\
\hline $\mathrm{a}, \mathrm{c}=1$ & 3.612 & 0.000 & 1.000 & 0.034 & 8.795 & 5.350 & 0.570 & 0.498 \\
\hline $\mathrm{a}, \mathrm{c}=0.5$ & 3.462 & 0.000 & 0.500 & 0.051 & 8.406 & 5.485 & 0.812 & 0.575 \\
\hline $\mathrm{a}, \mathrm{c}=0.2$ & 3.491 & 0.000 & 0.200 & 0.075 & 8.152 & 5.809 & 1.028 & 0.664 \\
\hline $\mathrm{a}, \mathrm{b}$ & 6.461 & -0.379 & 0.000 & 0.098 & 8.081 & 6.312 & 1.161 & 0.742 \\
\hline Taylor & 1.500 & 0.500 & 0.000 & 0.062 & 6.112 & 4.402 & 2.021 & 0.801 \\
\hline Taylor FD & 1.500 & 0.500 & 1.000 & 0.022 & 6.259 & 3.300 & 1.300 & 0.539 \\
\hline P-level & 4.831 & -0.106 & 0.000 & 0.032 & 8.986 & 5.316 & 0.563 & 0.494 \\
\hline \multicolumn{9}{|c|}{$\psi=0.2$} \\
\hline Opt plan & & & & 0.026 & 1.298 & 1.922 & 0.146 & 0.216 \\
\hline $\mathrm{a}, \mathrm{b}, \mathrm{c} 1, \mathrm{c} 2$ & 0.011 & 0.125 & 1.002 & 0.026 & 1.330 & 1.892 & 0.151 & 0.217 \\
\hline $\mathrm{a}, \mathrm{c}$ & 1.634 & 0.000 & 1.421 & 0.027 & 1.311 & 1.910 & 0.152 & 0.218 \\
\hline $\mathrm{a}, \mathrm{c}=1$ & 1.424 & 0.000 & 1.000 & 0.023 & 1.325 & 1.982 & 0.196 & 0.229 \\
\hline $\mathrm{a}, \mathrm{c}=0.5$ & 2.183 & 0.000 & 0.500 & 0.041 & 1.216 & 1.944 & 0.424 & 0.293 \\
\hline $\mathrm{a}, \mathrm{c}=0.2$ & 2.763 & 0.000 & 0.200 & 0.058 & 1.159 & 1.992 & 0.580 & 0.347 \\
\hline $\mathrm{a}, \mathrm{b}$ & 4.529 & -0.272 & 0.000 & 0.068 & 1.116 & 2.086 & 0.669 & 0.381 \\
\hline Taylor & 1.500 & 0.500 & 0.000 & 0.051 & 1.068 & 1.730 & 0.969 & 0.415 \\
\hline Taylor & 1.500 & 0.500 & 1.000 & 0.012 & 0.947 & 1.123 & 0.991 & 0.346 \\
\hline P-level & 1.631 & -0.053 & 0.000 & 0.023 & 1.334 & 1.986 & 0.193 & 0.229 \\
\hline
\end{tabular}

Notes: The table shows the level of welfare $\hat{W}^{c}$ and its component discounted variances achieved under the optimal plan and various rules. For further information, see the notes to Table 2. 
Table 4: Rules under Alternative Calibrations, Rule-of-Thumb Price Setting

\begin{tabular}{|c|c|c|c|c|c|c|c|c|}
\hline & $\mathrm{a}$ & $\mathrm{b}$ & $\mathrm{c}$ & $V\left[\pi_{t}\right]$ & $V\left[\Delta \pi_{t}\right]$ & $V\left[x_{t}\right]$ & $V\left[r_{t}\right]$ & $\hat{W}^{p}$ \\
\hline \multicolumn{9}{|c|}{ Alternative 1: $\lambda_{r}=0.077$} \\
\hline \multicolumn{9}{|c|}{$\lambda=1$} \\
\hline $\mathrm{a}, \mathrm{b}, \mathrm{c} 1, \mathrm{c} 2$ & 1.968 & 0.999 & 1.153 & 0.026 & 0.041 & 4.502 & 3.262 & 0.494 \\
\hline $\mathrm{a}, \mathrm{c}$ & 256.812 & 0.000 & 23.716 & 0.027 & 0.041 & 4.477 & 3.264 & 0.495 \\
\hline Taylor FD & 1.500 & 0.500 & 1.000 & 0.036 & 0.070 & 7.358 & 1.878 & 0.536 \\
\hline P-level & 31.084 & -0.559 & 0.000 & 0.017 & 0.050 & 4.621 & 3.644 & 0.521 \\
\hline \multicolumn{9}{|c|}{$\lambda=0.6$} \\
\hline$a, b, c 1, c 2$ & 2.397 & 1.033 & 1.146 & 0.011 & 0.010 & 4.583 & 3.454 & 0.509 \\
\hline $\mathrm{a}, \mathrm{c}$ & 58.516 & 0.000 & 2.182 & 0.004 & 0.009 & 4.787 & 3.612 & 0.522 \\
\hline Taylor FD & 1.500 & 0.500 & 1.000 & 0.016 & 0.016 & 7.876 & 1.887 & 0.559 \\
\hline P-level & 33.653 & 0.094 & 0.000 & 0.004 & 0.009 & 4.692 & 3.733 & 0.527 \\
\hline \multicolumn{9}{|c|}{$\lambda=0.2$} \\
\hline $\mathrm{a}, \mathrm{b}, \mathrm{c} 1, \mathrm{c} 2$ & 1.481 & 1.015 & 1.027 & 0.002 & 0.001 & 4.848 & 3.568 & 0.515 \\
\hline $\mathrm{a}, \mathrm{c}$ & 118.143 & 0.000 & 0.518 & 0.000 & 0.001 & 4.883 & 3.732 & 0.527 \\
\hline Taylor FD & 1.500 & 0.500 & 1.000 & 0.004 & 0.001 & 8.459 & 1.893 & 0.566 \\
\hline P-level & 94.487 & 0.266 & 0.000 & 0.000 & 0.001 & 4.882 & 3.660 & 0.521 \\
\hline \multicolumn{9}{|c|}{ Alternative 2: $\sigma=\omega=1$} \\
\hline \multicolumn{9}{|c|}{$\lambda=1$} \\
\hline $\mathrm{a}, \mathrm{b}, \mathrm{c} 1, \mathrm{c} 2$ & 0.170 & 0.086 & 1.041 & 0.011 & 0.020 & 0.632 & 0.022 & 0.068 \\
\hline $\mathrm{a}, \mathrm{c}$ & 1.572 & 0.000 & 1.690 & 0.012 & 0.020 & 0.634 & 0.021 & 0.069 \\
\hline Taylor FD & 1.500 & 0.500 & 1.000 & 0.007 & 0.014 & 0.469 & 0.238 & 0.102 \\
\hline P-level & 1.650 & -0.092 & 0.000 & 0.011 & 0.027 & 0.675 & 0.025 & 0.072 \\
\hline \multicolumn{9}{|c|}{$\lambda=0.6$} \\
\hline$a, b, c 1, c 2$ & 0.199 & 0.091 & 1.040 & 0.005 & 0.005 & 0.652 & 0.024 & 0.069 \\
\hline $\mathrm{a}, \mathrm{c}$ & 1.590 & 0.000 & 1.479 & 0.005 & 0.005 & 0.654 & 0.023 & 0.069 \\
\hline Taylor FD & 1.500 & 0.500 & 1.000 & 0.003 & 0.003 & 0.477 & 0.240 & 0.102 \\
\hline P-level & 1.471 & 0.002 & 0.000 & 0.004 & 0.005 & 0.684 & 0.027 & 0.072 \\
\hline \multicolumn{9}{|c|}{$\lambda=0.2$} \\
\hline $\mathrm{a}, \mathrm{b}, \mathrm{c} 1, \mathrm{c} 2$ & 0.251 & 0.098 & 1.025 & 0.001 & 0.000 & 0.685 & 0.022 & 0.064 \\
\hline $\mathrm{a}, \mathrm{c}$ & 1.944 & 0.000 & 1.143 & 0.001 & 0.000 & 0.704 & 0.020 & 0.065 \\
\hline Taylor FD & 1.500 & 0.500 & 1.000 & 0.001 & 0.000 & 0.490 & 0.230 & 0.097 \\
\hline P-level & 2.121 & 0.047 & 0.000 & 0.000 & 0.000 & 0.698 & 0.022 & 0.065 \\
\hline \multicolumn{9}{|c|}{ Alternative 3: $\rho_{r}=0.35$} \\
\hline \multicolumn{9}{|c|}{$\lambda=1$} \\
\hline $\mathrm{a}, \mathrm{b}, \mathrm{c} 1, \mathrm{c} 2$ & 0.642 & 0.326 & 1.153 & 0.13 & 0.096 & 10.591 & 1.926 & 1.097 \\
\hline $\mathrm{a}, \mathrm{c}$ & 46.366 & 0 & 13 & 0.135 & 0.096 & 10.497 & 1.927 & 1.097 \\
\hline Taylor FD & 1.5 & 0.5 & 1 & 0.052 & 0.075 & 7.429 & 3.345 & 1.2 \\
\hline P-level & 7.681 & -0.195 & 0 & 0.068 & 0.159 & 11.886 & 2.585 & 1.252 \\
\hline \multicolumn{9}{|c|}{$\lambda=0.6$} \\
\hline $\mathrm{a}, \mathrm{b}, \mathrm{c} 1, \mathrm{c} 2$ & 0.953 & 0.345 & 1.196 & 0.09 & 0.035 & 10.889 & 2.115 & 1.151 \\
\hline $\mathrm{a}, \mathrm{c}$ & 22.647 & 0 & 4.571 & 0.061 & 0.034 & 12.142 & 2.143 & 1.187 \\
\hline Taylor FD & 1.5 & 0.5 & 1 & 0.029 & 0.02 & 7.93 & 3.41 & 1.238 \\
\hline P-level & 8.218 & 0.033 & 0 & 0.02 & 0.032 & 12.087 & 2.717 & 1.277 \\
\hline \multicolumn{9}{|c|}{$\lambda=0.2$} \\
\hline $\mathrm{a}, \mathrm{b}, \mathrm{c} 1, \mathrm{c} 2$ & 0.549 & 0.348 & 1.035 & 0.018 & 0.003 & 12.447 & 2.441 & 1.216 \\
\hline $\mathrm{a}, \mathrm{c}$ & 27.133 & 0 & 0.73 & 0.002 & 0.002 & 12.956 & 2.712 & 1.28 \\
\hline Taylor FD & 1.5 & 0.5 & 1 & 0.009 & 0.002 & 8.737 & 3.479 & 1.262 \\
\hline P-level & 20.165 & 0.124 & 0 & 0.002 & 0.002 & 12.813 & 2.626 & 1.254 \\
\hline
\end{tabular}


Table 5: Rules under Alternative Calibrations, Rule-of-Thumb Consumption

\begin{tabular}{|c|c|c|c|c|c|c|c|c|}
\hline & $\mathrm{a}$ & $\mathrm{b}$ & $\mathrm{c}$ & $V\left[\pi_{t}\right]$ & $V\left[\Delta y_{t}\right]$ & $V\left[x_{t}\right]$ & $V\left[r_{t}\right]$ & $\hat{W}^{c}$ \\
\hline \multicolumn{9}{|c|}{ Alternative 1: $\lambda_{r}=0.077$} \\
\hline \multicolumn{9}{|c|}{$\psi=1$} \\
\hline $\mathrm{a}, \mathrm{b}, \mathrm{c} 1, \mathrm{c} 2$ & 1.968 & 0.999 & 1.153 & 0.026 & 11.879 & 4.502 & 3.262 & 0.494 \\
\hline $\mathrm{a}, \mathrm{c}$ & 256.812 & 0.000 & 23.716 & 0.027 & 11.783 & 4.477 & 3.264 & 0.495 \\
\hline Taylor FD & 1.500 & 0.500 & 1.000 & 0.036 & 18.410 & 7.358 & 1.878 & 0.536 \\
\hline P-level & 31.084 & -0.559 & 0.000 & 0.017 & 12.390 & 4.621 & 3.644 & 0.521 \\
\hline \multicolumn{9}{|c|}{$\psi=0.6$} \\
\hline $\mathrm{a}, \mathrm{b}, \mathrm{c} 1, \mathrm{c} 2$ & 138.547 & -3.479 & 12.403 & 0.019 & 5.578 & 2.925 & 1.608 & 0.329 \\
\hline $\mathrm{a}, \mathrm{c}$ & 21.849 & 0.000 & 2.737 & 0.019 & 5.668 & 2.928 & 1.606 & 0.329 \\
\hline Taylor FD & 1.500 & 0.500 & 1.000 & 0.022 & 6.259 & 3.300 & 1.300 & 0.332 \\
\hline P-level & 14.674 & -0.225 & 0.000 & 0.015 & 5.683 & 2.985 & 1.769 & 0.341 \\
\hline \multicolumn{9}{|c|}{$\psi=0.2$} \\
\hline $\mathrm{a}, \mathrm{b}, \mathrm{c} 1, \mathrm{c} 2$ & 0.026 & 0.327 & 1.002 & 0.013 & 1.112 & 1.416 & 0.510 & 0.174 \\
\hline $\mathrm{a}, \mathrm{c}$ & 4.695 & 0.000 & 1.367 & 0.013 & 1.082 & 1.436 & 0.520 & 0.175 \\
\hline Taylor FD & 1.500 & 0.500 & 1.000 & 0.012 & 0.947 & 1.123 & 0.991 & 0.189 \\
\hline P-level & 4.556 & -0.070 & 0.000 & 0.012 & 1.074 & 1.458 & 0.572 & 0.178 \\
\hline \multicolumn{9}{|c|}{ Alternative 2: $\sigma=\omega=1$} \\
\hline \multicolumn{9}{|c|}{$\psi=1$} \\
\hline $\mathrm{a}, \mathrm{b}, \mathrm{c} 1, \mathrm{c} 2$ & 0.170 & 0.086 & 1.041 & 0.011 & 58.028 & 0.632 & 0.022 & 0.068 \\
\hline $\mathrm{a}, \mathrm{c}$ & 1.572 & 0.000 & 1.690 & 0.012 & 57.965 & 0.634 & 0.021 & 0.069 \\
\hline Taylor FD & 1.500 & 0.500 & 1.000 & 0.007 & 49.638 & 0.469 & 0.238 & 0.102 \\
\hline P-level & 1.650 & -0.092 & 0.000 & 0.011 & 59.975 & 0.675 & 0.025 & 0.072 \\
\hline \multicolumn{9}{|c|}{$\psi=0.6$} \\
\hline $\mathrm{a}, \mathrm{b}, \mathrm{c} 1, \mathrm{c} 2$ & 0.019 & 0.183 & 1.005 & 0.005 & 0.956 & 0.095 & 0.015 & 0.042 \\
\hline $\mathrm{a}, \mathrm{c}$ & 2.175 & 0.000 & 2.046 & 0.005 & 0.957 & 0.095 & 0.015 & 0.043 \\
\hline Taylor FD & 1.500 & 0.500 & 1.000 & 0.002 & 0.885 & 0.070 & 0.079 & 0.051 \\
\hline P-level & 1.449 & -0.120 & 0.000 & 0.006 & 1.003 & 0.110 & 0.019 & 0.046 \\
\hline \multicolumn{9}{|c|}{$\psi=0.2$} \\
\hline $\mathrm{a}, \mathrm{b}, \mathrm{c} 1, \mathrm{c} 2$ & 0.124 & 0.041 & 1.036 & 0.004 & 0.227 & 0.098 & 0.011 & 0.052 \\
\hline $\mathrm{a}, \mathrm{c}$ & 0.619 & 0.000 & 1.244 & 0.005 & 0.224 & 0.100 & 0.011 & 0.052 \\
\hline Taylor FD & 1.500 & 0.500 & 1.000 & 0.002 & 0.200 & 0.079 & 0.184 & 0.085 \\
\hline P-level & 0.715 & -0.026 & 0.000 & 0.005 & 0.226 & 0.102 & 0.017 & 0.054 \\
\hline \multicolumn{9}{|c|}{ Alternative 3: $\rho_{r}=0.35$} \\
\hline \multicolumn{9}{|c|}{$\psi=1$} \\
\hline $\mathrm{a}, \mathrm{b}, \mathrm{c} 1, \mathrm{c} 2$ & 0.642 & 0.326 & 1.153 & 0.13 & 21.027 & 10.591 & 1.926 & 1.097 \\
\hline $\mathrm{a}, \mathrm{c}$ & 46.366 & 0 & 13 & 0.135 & 20.794 & 10.497 & 1.927 & 1.097 \\
\hline Taylor FD & 1.5 & 0.5 & 1 & 0.052 & 15.573 & 7.429 & 3.345 & 1.2 \\
\hline P-level & 7.681 & -0.195 & 0 & 0.068 & 24.012 & 11.886 & 2.585 & 1.252 \\
\hline \multicolumn{9}{|c|}{$\psi=0.6$} \\
\hline $\mathrm{a}, \mathrm{b}, \mathrm{c} 1, \mathrm{c} 2$ & 102.269 & -3.427 & 26.78 & 0.105 & 9.013 & 7.249 & 1.225 & 0.816 \\
\hline $\mathrm{a}, \mathrm{c}$ & 6.966 & 0 & 2.771 & 0.106 & 9.074 & 7.248 & 1.225 & 0.818 \\
\hline Taylor FD & 1.5 & 0.5 & 1 & 0.04 & 6.129 & 4.181 & 2.831 & 0.96 \\
\hline P-level & 4.588 & -0.167 & 0 & 0.068 & 9.778 & 7.9 & 1.613 & 0.909 \\
\hline \multicolumn{9}{|c|}{$\psi=0.2$} \\
\hline $\mathrm{a}, \mathrm{b}, \mathrm{c} 1, \mathrm{c} 2$ & 1.251 & 0.009 & 1.303 & 0.093 & 2.043 & 4.903 & 0.614 & 0.573 \\
\hline $\mathrm{a}, \mathrm{c}$ & 1.562 & 0 & 1.4 & 0.095 & 2.014 & 4.879 & 0.615 & 0.573 \\
\hline Taylor FD & 1.5 & 0.5 & 1 & 0.035 & 1.243 & 2.308 & 3.114 & 0.942 \\
\hline P-level & 1.754 & -0.124 & 0 & 0.076 & 2.076 & 5.186 & 0.786 & 0.612 \\
\hline
\end{tabular}


Table 6: Optimal Rules under Rule-of-Thumb Price Setting with Inefficient Supply Shocks

\begin{tabular}{|c|c|c|c|c|c|c|c|c|}
\hline & $\mathrm{a}$ & $\mathrm{b}$ & $\mathrm{c}$ & $V\left[\pi_{t}\right]$ & $V\left[\Delta \pi_{t}\right]$ & $V\left[x_{t}\right]$ & $V\left[r_{t}\right]$ & $\hat{W}^{p}$ \\
\hline \multicolumn{8}{|c|}{$\lambda=1$} \\
\hline a,b,c1,c2 & 0.642 & 0.326 & 1.153 & 0.157 & 0.291 & 10.213 & 0.986 & 0.883 \\
a,b,c & 1.126 & 0.316 & 1.316 & 0.175 & 0.307 & 10.332 & 0.958 & 0.900 \\
a,c & 4.204 & 0.000 & 1.946 & 0.109 & 0.225 & 18.020 & 0.657 & 1.134 \\
Taylor FD & 1.500 & 0.500 & 1.000 & 0.144 & 0.302 & 7.720 & 1.926 & 0.971 \\
P-level & 2.001 & 0.182 & 0.000 & 0.122 & 0.302 & 13.919 & 1.241 & 1.087 \\
\hline \multicolumn{8}{|c|}{$\lambda=0.6$} \\
\hline a,b,c1,c2 & 0.694 & 0.341 & 1.133 & 0.271 & 0.353 & 13.204 & 1.087 & 1.522 \\
a,b,c & 1.295 & 0.288 & 1.400 & 0.286 & 0.349 & 14.007 & 1.026 & 1.558 \\
a,c & 0.854 & 0.000 & 0.920 & 0.184 & 0.307 & 32.599 & 0.311 & 2.143 \\
Taylor FD & 1.500 & 0.500 & 1.000 & 0.331 & 0.383 & 9.511 & 2.091 & 1.670 \\
P-level & 1.156 & 0.284 & 0.000 & 0.211 & 0.323 & 18.366 & 1.435 & 1.763 \\
\hline \multicolumn{8}{|c|}{$\lambda=0.2$} \\
\hline a,b,c1,c2 & 0.495 & 0.017 & 0.593 & 0.904 & 0.432 & 56.161 & 0.723 & 6.406 \\
a,b,c & 1.114 & 0.251 & 1.264 & 0.993 & 0.430 & 33.980 & 1.687 & 5.636 \\
a,c & 0.361 & 0.000 & 0.695 & 0.910 & 0.433 & 56.220 & 0.699 & 6.415 \\
Taylor FD & 1.500 & 0.500 & 1.000 & 1.511 & 0.454 & 20.126 & 3.236 & 5.999 \\
P-level & 0.554 & 0.292 & 0.000 & 0.951 & 0.461 & 59.053 & 1.396 & 6.925 \\
\hline
\end{tabular}


Figure 1: Impulse Responses to a Natural Rate of Interest Shock under Optimal Policy

\section{Rule-of-Thumb Price Setting}
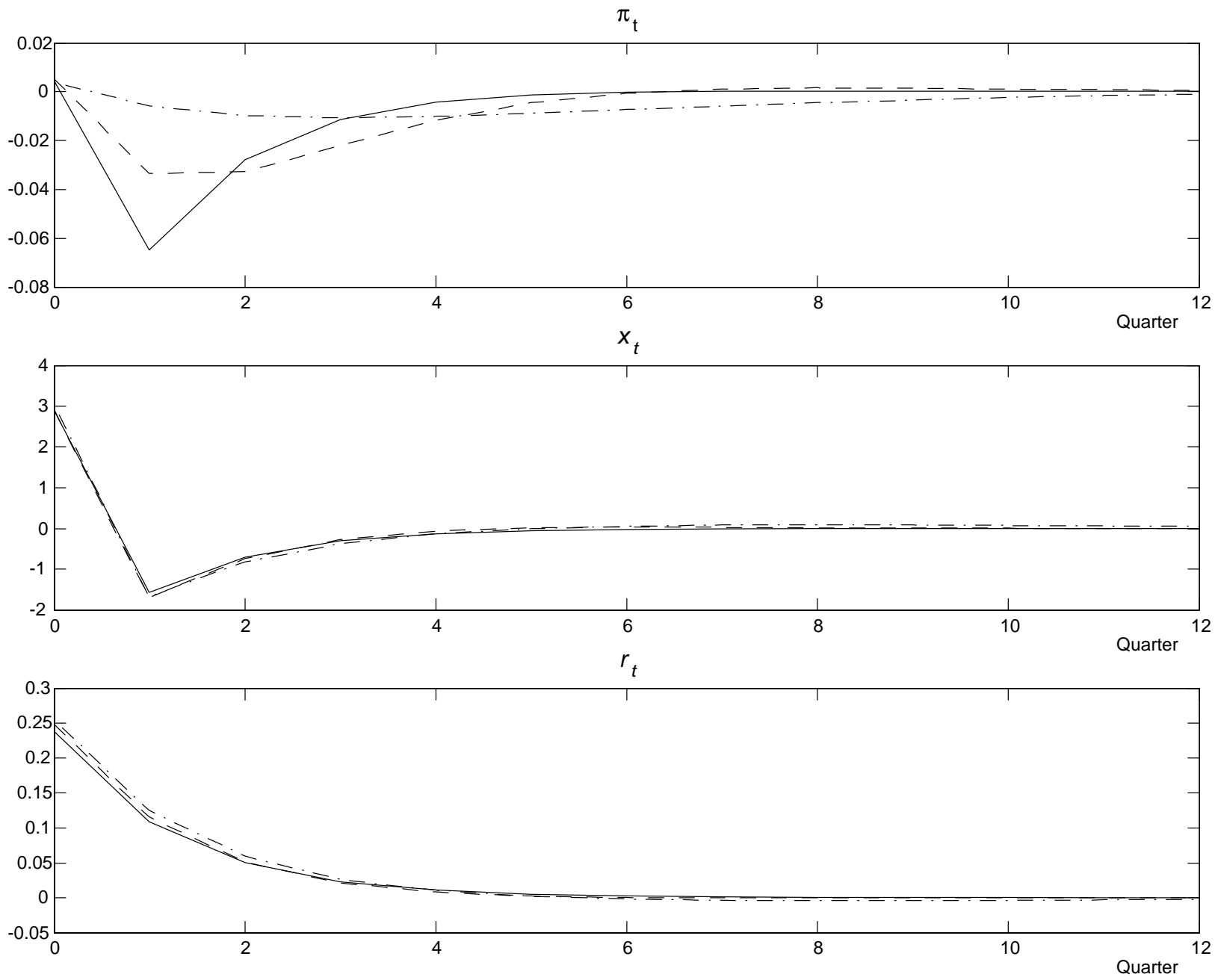

Notes: The figure maps out the impulse responses of the endogenous variables to a one-standard deviation shock to the innovation in the natural rate of interest at time 0 . The different lines correspond to different values of $\lambda$ : 1.0 (solid), 0.6 (dash) and 0.2 (dash-dot). One period is equal to a quarter. Inflation and the interest rate are expressed in annualised percentages, the output gap in percentages. 


\section{Figure 2: Standard Deviation of the Natural Rate of Interest}

\section{Rule-of-Thumb Consumption}

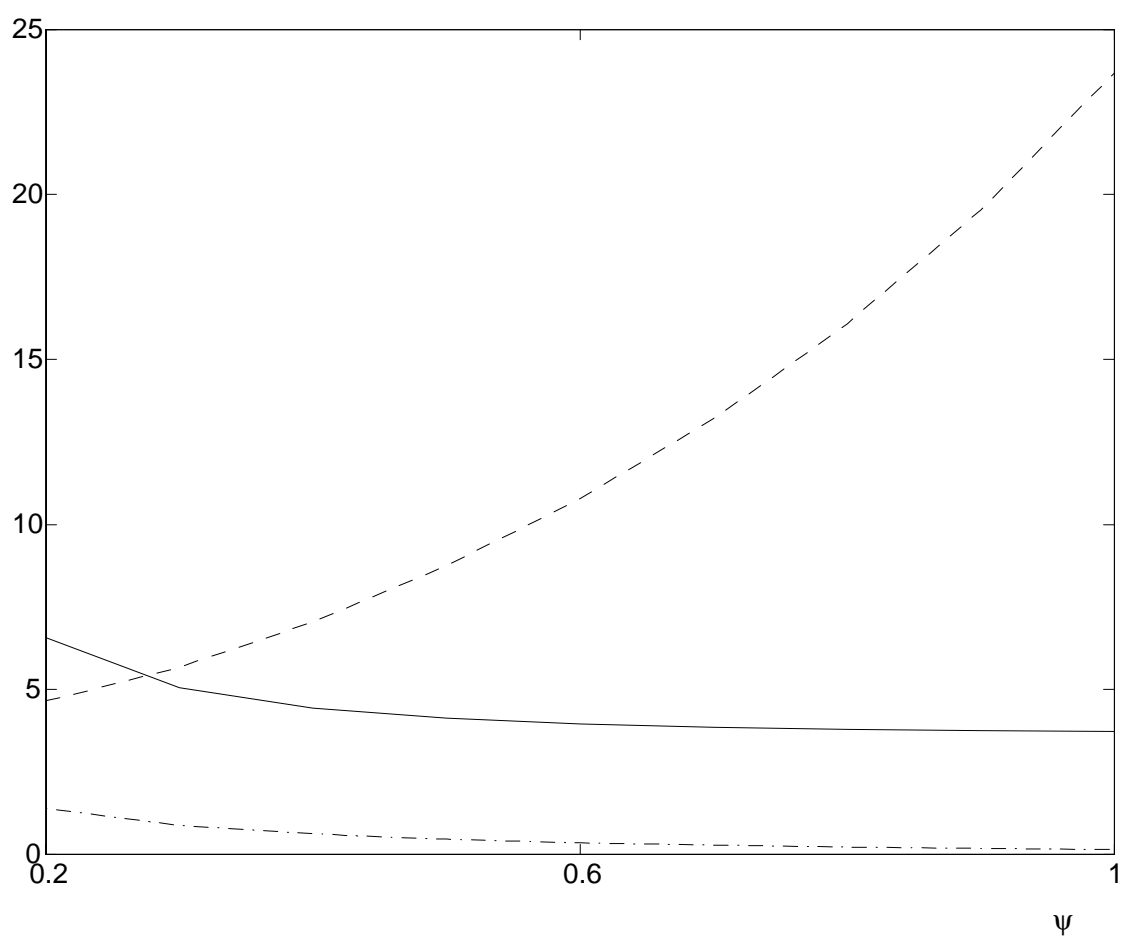

Notes: The figure shows the unconditional standard deviation of the natural rate of interest $\tilde{r}_{t}^{n}$ (solid) with respect to $\psi$. Also shown is the component of this standard deviation related to the conditional expectation of the shock processes, i.e. $\tilde{r}_{t}^{n} / \tilde{\sigma}$ (dash) and the parameter $\tilde{\sigma}$ (dash-dot). The natural rate of interest is expressed in annualised percentages. 


\section{Figure 3: Impulse Responses to a Marginal Utility of Consumption Shock under Optimal Policy}

\section{Rule-of-Thumb Consumption}
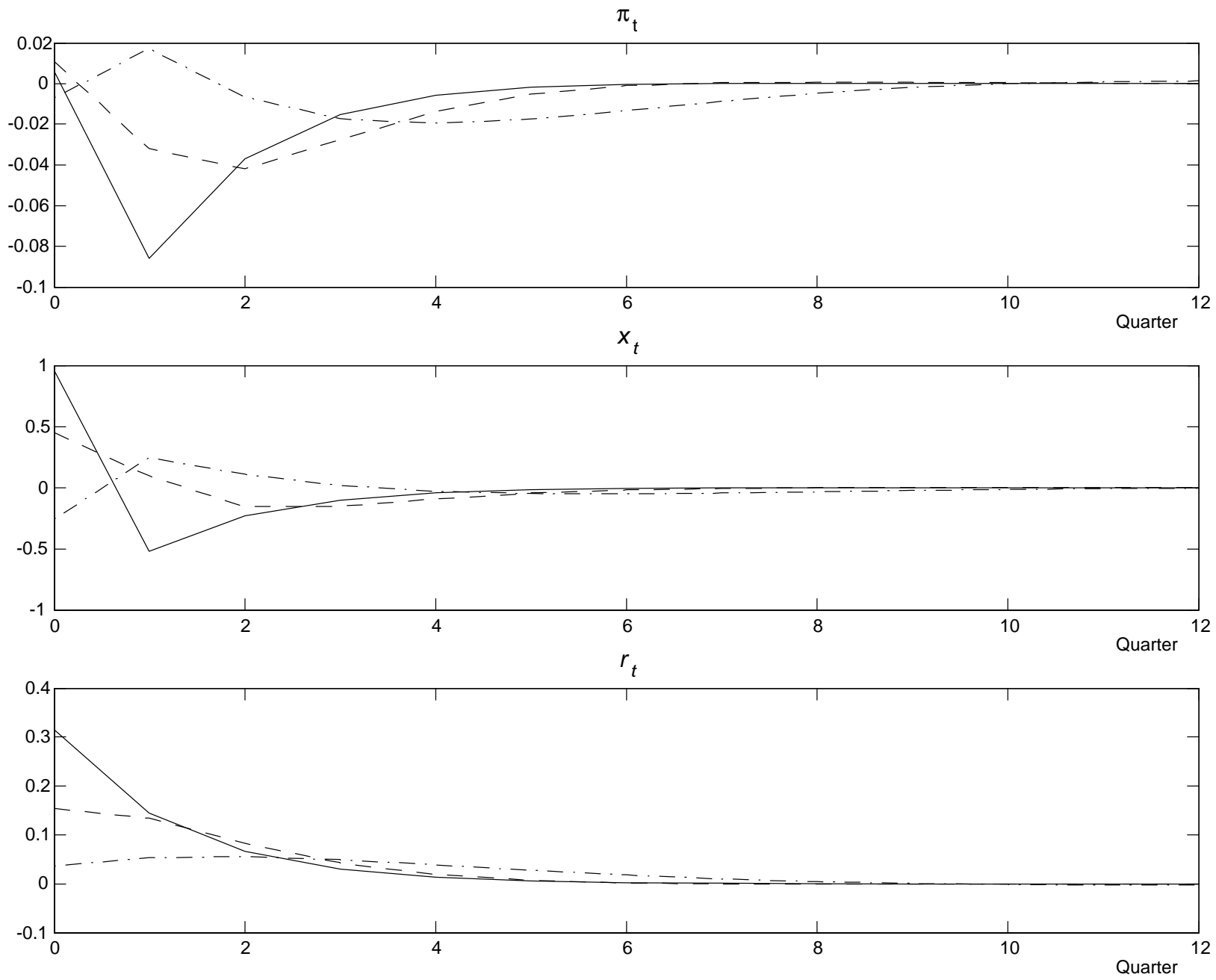

Notes: The figure maps out the impulse responses of the endogenous variables to a one-unit shock to the innovation in $g_{t}$ that is orthogonal to $z_{t}$ at time 0 . The different lines correspond to different values of $\psi$ : 1.0 (solid), 0.6 (dash) and 0.2 (dash-dot). One period is equal to a quarter. Inflation and the interest rate are expressed in annualised percentages, the output gap in percentages. 